\title{
A review of friction models in interacting joints for durability design
}

\author{
Zulfiqar A. KHAN*, Vivek CHACKO, Hammad NAZIR \\ NanoCorr, Energy \& Modelling (NCEM) Research, Department of Design \& Engineering, Bournemouth University, Bournemouth, United Kingdom \\ Received: 31 July 2016 / Revised: 26 October 2016 / Accepted: 16 December 2016 \\ (C) The author(s) 2017. This article is published with open access at Springerlink.com
}

\begin{abstract}
This paper presents a comprehensive review of friction modelling to provide an understanding of design for durability within interacting systems. Friction is a complex phenomenon and occurs at the interface of two components in relative motion. Over the last several decades, the effects of friction and its modelling techniques have been of significant interests in terms of industrial applications. There is however a need to develop a unified mathematical model for friction to inform design for durability within the context of varying operational conditions. Classical dynamic mechanisms model for the design of control systems has not incorporated friction phenomena due to non-linearity behaviour. Therefore, the tribological performance concurrently with the joint dynamics of a manipulator joint applied in hazardous environments needs to be fully analysed. Previously the dynamics and impact models used in mechanical joints with clearance have also been examined. The inclusion of reliability and durability during the design phase is very important for manipulators which are deployed in harsh environmental and operational conditions. The revolute joint is susceptible to failures such as in heavy manipulators these revolute joints can be represented by lubricated conformal sliding surfaces. The presence of pollutants such as debris and corrosive constituents has the potential to alter the contacting surfaces, would in turn affect the performance of revolute joints, and puts both reliability and durability of the systems at greater risks of failure. Key literature is identified and a review on the latest developments of the science of friction modelling is presented here. This review is based on a large volume of knowledge. Gaps in the relevant field have been identified to capitalise on for future developments. Therefore, this review will bring significant benefits to researchers, academics and industry professionals.
\end{abstract}

Keywords: friction; dynamics; joint clearance; numerical models; impact; durability

\section{Introduction}

Friction is a ubiquitous phenomenon which occurs at the interface of two surfaces in physical contact and in relative motion. It may be at times beneficial and/or detrimental in other scenarios. The phenomenon of friction is complex because it has time dependent non-linear characteristics and it is influenced by multiple factors. Friction phenomenon applies to scales ranging from nanometre level interactions to micron level interfaces to large geological interactions [1,2]. Friction is directly linked to the durability and reliability of interacting systems and if it is not fully optimised then it leads to significant efficiency losses. According to the Jost report of 1966, "a sizeable portion of the GDP of a nation is spent in alleviating friction and its effects namely wear". Although tribology is a relatively new area, it is formed from a confluence of theory and empiricism, continued experimental analyses, mechanics, surface engineering, chemical interactions and more recently computational methodology. Since the phenomenon has both widespread and deep-rooted influence, this review paper seeks to gain an insight into the history of the development of friction and

* Corresponding author: Zulfiqar A. KHAN, E-mail: zkhan@bournemouth.ac.uk 


\section{List of symbols}

A Parameter in Bliman-Sorin model

B Parameter in Bliman-Sorin model

$\boldsymbol{B}(\dot{\theta}) \quad$ Frictional torque matrix

$c_{\mathrm{d}} \quad$ Dynamic friction coefficient in modified

coulomb friction law

$c_{\mathrm{f}} \quad$ Friction coefficient in modified coulomb

friction law

C Parameter in Bliman-Sorin model

$C(\boldsymbol{\theta}, \dot{\theta})$

Coriolis and centripetal effects

$C_{i}$

Coordinate systems of the multibody with

clearance

$D$

Damping coefficient

$D(\theta) \quad$ Inertia matrix

DLC Diamond like coating

DV

$E^{*}$

Limit velocity in Karnopp model

Effective modulus of elasticity

$e_{y} \quad$ The distance between centres along the ordinate

$e_{x} \quad$ The distance between centres along the abscissa

$e_{i j}$ Vector distance along displacement of centres

Friction force generated by friction model Force applied on the rigid body 1

Force applied on the rigid body 2

Coulomb friction force

Hysteresis force in the Leuven Model

Force applied by external actuator

Friction force (Seven Parameter model)

$F_{\mathrm{f}}$

Hysteresis force in the Leuven Model

$F_{\mathrm{h}}$

$F_{\mathrm{n}}, F_{\mathrm{N}}$

Normal force at contact

$F_{\mathrm{s}}$

Static friction coefficient or Stribeck friction

coefficient

$F_{\mathrm{s}, \mathrm{a}} \quad$ Magnitude of the Stribeck friction at the end of the previous sliding period (Seven Parameter model)

$F_{\mathrm{s}, \infty} \quad$ Magnitude of the Stribeck friction after a long time at rest (Seven Parameter model)

$F_{\mathrm{T}}$

Tangential friction force in modified coulomb model

$v_{\mathrm{s}}$

$v_{\mathrm{T}}$

$\dot{x}$

$\dot{x}_{\mathrm{s}}$

$x$

X

X

$X_{1}$

$X_{2}$

$Y$

$z$

$\alpha$

$\beta$

$\Gamma$

$F_{\mathrm{v}} \quad$ Viscous friction force

$G(\theta) \quad$ Gravity forces

$k \quad$ Spring constant

K Stiffness at contact

M Mass matrix

n Normal along the contact

$n \quad$ Shape curve transitioning coefficient

$N \quad$ Exponential coefficient

$\mathrm{O}$ Origin of the global coordinate system
$\begin{array}{ll}\mathrm{O}_{i} & \text { Coordinate system } i \text { of the journal } \\ O_{j} & \text { Coordinate system } j \text { of the journal }\end{array}$

$\mathrm{O}_{j}$

PEEK

$\ddot{q}$

$r$

$R_{\mathrm{o}}$

$R_{\mathrm{i}}$

RI

Polyether ether ketone

Generalised acceleration state vector

Clearance between the bodies at contact

Radius of the outer bearing

Radius of the journal

Reset Integrator model

Space variable in Bliman Sorin model

Shape transitioning curve

Tangent at contact point

Dwell time (Seven parameter model)

Time constant of frictional memory

Velocity at contact of the moving body

Threshold values of velocities for dynamic correction factor in the modified Coulomb friction model

State variable in Bliman Sorin model

Relative tangential velocity at contact

Sliding velocity

Characteristic velocity of the Stribeck friction

Sliding distance

Hysteresis damping factor

$X$ axis of the global coordinate system

Displacement of the rigid body 1

Displacement of the rigid body 2

$\mathrm{Y}$ axis of the global coordinate system

State parameter in friction model

Baumgarte coefficients

Baumgarte coefficients

Input matrix

Time parameter of the rising static friction

(Seven parameter model)

Time derivative of deflection at contact

Deflection at contact/Penetration depth of journal and bearing

Lagrange multiplier

Jacobian matrix for constraint equations Coefficient accompanying the state variable, an equivalent stiffness for position-force relationship at velocity reversal (LuGre model), the tangential stiffness of the static contact

$\sigma_{1} \quad$ Micro-viscous friction coefficient

$\sigma_{2} \quad$ Viscous friction coefficient

$\mu \quad$ Coefficient of friction

$\tau \quad$ Joint torque

$\tau_{\mathrm{L}} \quad$ Torque from external load 
dynamic modelling and to summarize various friction models and their characteristics.

Friction occurs in both prismatic and revolute mechanisms contacts. In revolute joints, increasing the diameter of the contacts can effectively reduce the contact pressure. However, the sliding distance increases which may result in accelerated wear [3]. The nature of contact in revolute joints in manipulators can vary between conformal and non-conformal contacts depending on whether sliding bearings or anti-friction bearings have been used. The nature of the clearance existing at the revolute joint contact determines whether the contact is continuous or non-continuous contact during its operation. Continuous contacts can be modelled with a revolute friction model. The non-continuous models require contact models that capture the model dynamics as well as follow energy conservation and are therefore much more tedious to model. Both these models have been examined in Sections 4.1 and 4.2 of this paper.

The focus of several recent researches has been the modelling of friction in manipulators [4-8]. The extended problem also requires the formulation of a suitable control system. Some researchers have tried to use an un-modelled dynamics approach $[9,10]$. Friction introduces non-linearity into the dynamics equation, which physically implies phenomena such as stick-slip in relative motion, limits cycles and introduces difficulties in positioning the end effector of the manipulator. However, as of now, friction models are imperative in analysing any mechanism.

Friction modelling has progressed from specific models analysing friction at the interface of geometries [11-14], to the analysis of friction at manipulator joints $[4,7,15]$ with clearance and their kinematics and dynamic [16-25]. Marques et al. [26] have recently surveyed friction models in single degree of freedom in planar systems. Lately, researches such as Mukras et al. $[27,28]$ have analysed the computation of joint wear calculation along with dynamics. The progress of research is seen in the integration of multiple disciplines that include tribology, computational mechanics, control systems, surface interaction and chemical interactions.

This review converges to manipulator joints used in mechanical equipment as excavators and search and rescue smart mechanical systems. Excavator is a commonly deployed platform in disaster sites. However there has been a rise in accident numbers in controlled construction environments with respect to the number of units being used, which has been a major health and safety concern [29]. The manipulator kinematics has been introduced by Koivo et al. [30], extended to dynamics by Vähä and Koivo [31,32]. Subsequent works have followed the modelling approach proposed by these researchers in attempting to develop the dynamics and control methods however until date only some studies based on the real arm $[33,34]$ have shown partial success in implementation. The non-linearity of the dynamics formulation makes the numerical solution both complex and computationally expensive. The computational effort increases with the increase in the degree of freedom, e.g., increase in the number of links in the manipulator, transformation from simple open chain manipulator to a closed loop mechanism and with the introduction of the nonlinear friction component into the dynamic equation. According to Haessig and Friedland, "friction is the nemesis of precision control". The phenomenon of friction is often ignored in control theory because of its intricacy. For precision control applications, however, the effect of friction cannot be ignored. The main impediment can be attributed to the complexity of dynamics, i.e., the non-linearity in the loads and more importantly the question of mimicking a human being. In this respect it is worth noting that Bilandi et al. [4, 15, 35] have studied the friction in an excavator arm.

Moreover, physical failure of a robot is a major obstacle in search and rescue missions [36,37] and this can only be alleviated through the study of the manipulator mechanism design from the material science viewpoint, the need for which can be substantiated by the growing attention on natural and man-made disasters and the efforts to minimise causalities. The ingress and egress of rescuers is not the only cause for concern in such sites, and bringing such sites back to normalcy is part of the post-disaster operation. For these the use of equipment is very much a necessity both to speed up operation and to reduce risk to human beings however the risk reduction also entails focus on the manipulator mechanism to perform in those environments without catastrophic failures. Very few researches have focussed on this 
aspect since the focus of search and rescue operations has been to detect and replace of live rescuers (human and dogs) with robots. When large quantities of chemicals were found in large radius after the WTC incident [38], the effect of corrosion inducing species on the operating equipment needs to be examined too. Stalwart researchers such as Blau [39] recognise that most appropriate method for determining the effect of friction and its effects and quantifying it, is still in experimentation and analysis also elucidates that the effects of environment on such mechanical joints need attention. Recently, holistic models combining dynamics, friction and wear have begun to appear in literature.

A multi-disciplinary approach (Fig. 1) is needed to fully analyse the problem and to devise a meaningful solution for the dynamics and control of manipulators. Friction and wear effects in the manipulators incorporating environmental effects need to be fully studied. With the increase in available computational power, a transition from simple analytical to complex numerical formulations of friction problem, with an analogous improvement in the range and precision of friction models has been looked. As part of the effort, a detailed literature survey is presented here, which provides an in-depth insight into the modelling of dynamics with a focus on friction (Fig. 2). A similar review for biodiesels has been presented recently [40]. The future research directions and gaps have been identified and presented for future reference.

Multidisciplinary techniques to advance design methods to improve efficiency, reliability and durability of contacting surfaces are explored in the literature [41-44]. The outline of the survey methodology has been given in the next section.

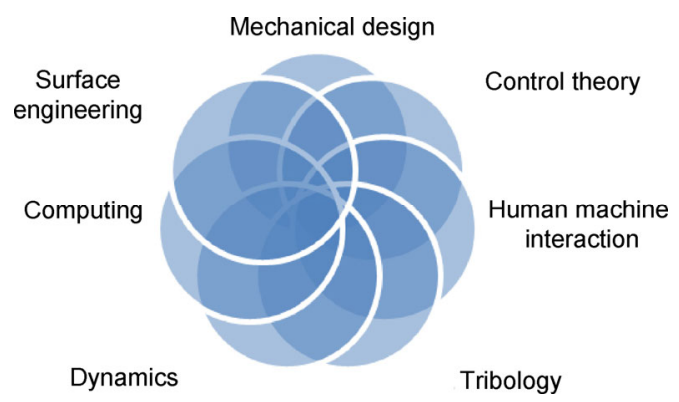

Fig. 1 The area of manipulator design modelling and control arises from the confluence of several branches of engineering and science.

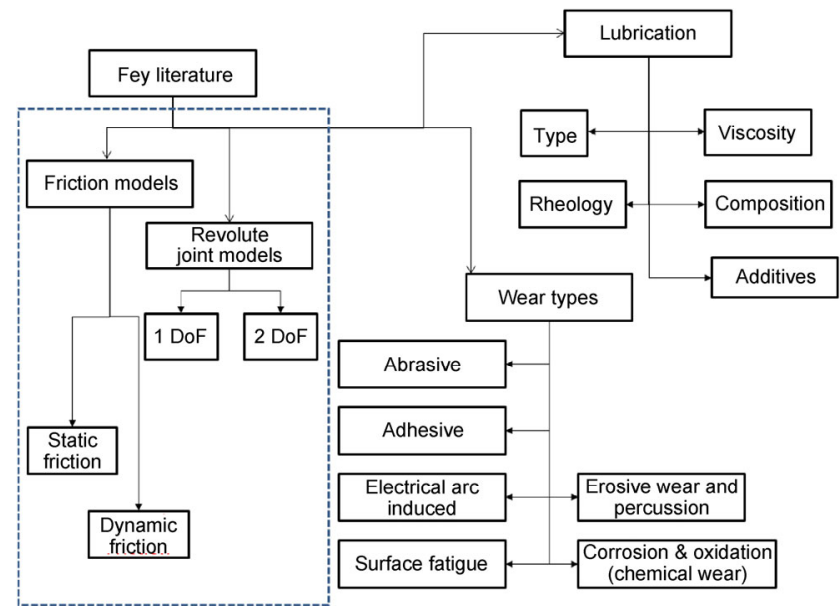

Fig. 2 Factors influencing the manipulator mechanism. This blue box highlights the focus areas of this paper, i.e., dynamics and friction with reference to manipulator methodology.

\section{Review methodology}

The review of literature was conducted beginning from important literature by citation index and relevance. Amstrong-Helouvry et al. [45] revealed that a growth of 700 articles in tribology is expected yearly. With the available volume of literature, it would be an impossible task to encompass all research areas. This review focuses on dynamics and friction modelling which applies to the specific case of the manipulator arm deployed in harsh environments. Kinematics, dynamics and control of such robotic manipulators have been the subject of research interest in the recent few decades. Important keywords are identified (refer to keywords above) in relevant cited publications. A search on (friction models*, static ${ }^{*}$ and dynamics*), in June 2016 revealed the following statistics (Fig. 3). The focus of this paper is on the development of the techniques of modelling mechanisms, the recognition and the inclusion of friction into dynamic modelling, some necessary aspects of control and the evolution of the modelling methodology of friction along with wear and lubrication which form an integral portion of this science. At the outset, the following aspects are addressed, including (1) to summarize the research development and timeline, (2) to identify key review papers, (3) to enumerate the important numerical models and (4) to identify future research directions. The history of manipulator modelling is outlined in the forthcoming section. 


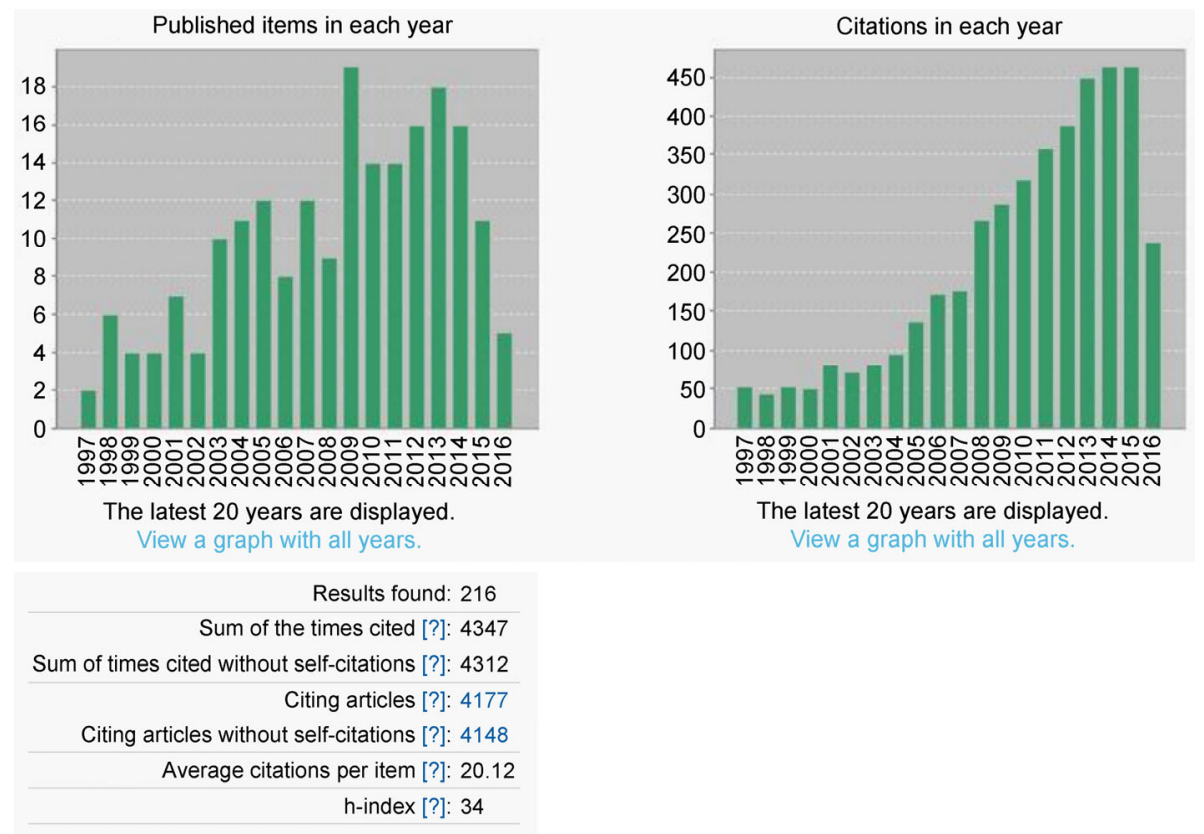

Fig. 3 Articles published in the domain containing keywords of friction models, static and dynamic.

\section{History of dynamic modelling}

An encapsulated version of the history of mechanics of manipulators and numerical modelling is presented here. Progress in manipulator modelling can be seen with the increase in modelling complexities from the late 1980s to present date. History of multibody dynamics has been presented by Rahnejat [46] and Schiehlen [47]. Computational dynamics has made rapid progress in the $20^{\text {th }}$ century. Detailed modelling methodology from the robotics and control perspective has been presented by Siciliano and Khatib in their book [48]. Uicker et al. [49] have provided the fundamental theory of mechanisms. Computational aspects have also been described by Groover and Zimmers Jr. [50]. Dynamics of parallel manipulator with friction has been presented by Farhat et al. [51]. Friction in space manipulator has been presented in Hachkowski et al. [52]. With the advent of computers and increased availability of computing power, several techniques incorporating engineering design techniques have evolved. The use of CAD and multibody dynamics in the design, simulation and analysis of mechanisms has greatly contributed to the efficiency of the entire process [53].

The free body diagram of a robot with manipulator is given in Fig. 4. The first step in the modelling of any mechanism is the development of the kinematic relationship between links, assigning the appropriate relations between links. Planar kinematics of a manipulator arm with three revolute joints has been presented in Ref. [30] following the Denavit-Hartenberg [54] convention of coordinate system assignment. Computation of the forward kinematics of such mechanisms is straightforward. However, in the case of the inverse kinematics of multi-link mechanisms multiple solutions exist and computation of the inverse kinematics is difficult.

Kinematic analyses are devoid of force calculations. Dynamic analyses which include the force calculations are presented in literature $[56,57]$. Dynamics of mechanisms can be modelled by using Newton Euler method [31], Euler Lagrange method [58], Gibbs Appel method [59], or Kane's equation [60, 61]. Selection of method used to model the system dynamics depends on the application and complexity of the mechanism design. The dynamic model of the manipulator is based on Ref. [31]:

$$
D(\theta) \dot{\theta}+C(\theta, \dot{\theta}) \dot{\theta}+G(\theta)+B(\dot{\theta})=\Gamma \tau-\tau_{\mathrm{L}}
$$

where $\theta=\left[\begin{array}{llll}\boldsymbol{\theta}_{1} & \boldsymbol{\theta}_{2} & \boldsymbol{\theta}_{3} & \boldsymbol{\theta}_{4}\end{array}\right]^{\mathrm{T}}$ is the vector representation of joint angles, $\boldsymbol{D}(\boldsymbol{\theta})$ represents inertia, $\boldsymbol{C}(\boldsymbol{\theta}, \dot{\boldsymbol{\theta}})$ represents Corioli's and centripetal effects, $G(\theta)$ represents gravity forces, $\boldsymbol{B}(\dot{\boldsymbol{\theta}})$ represents frictional 


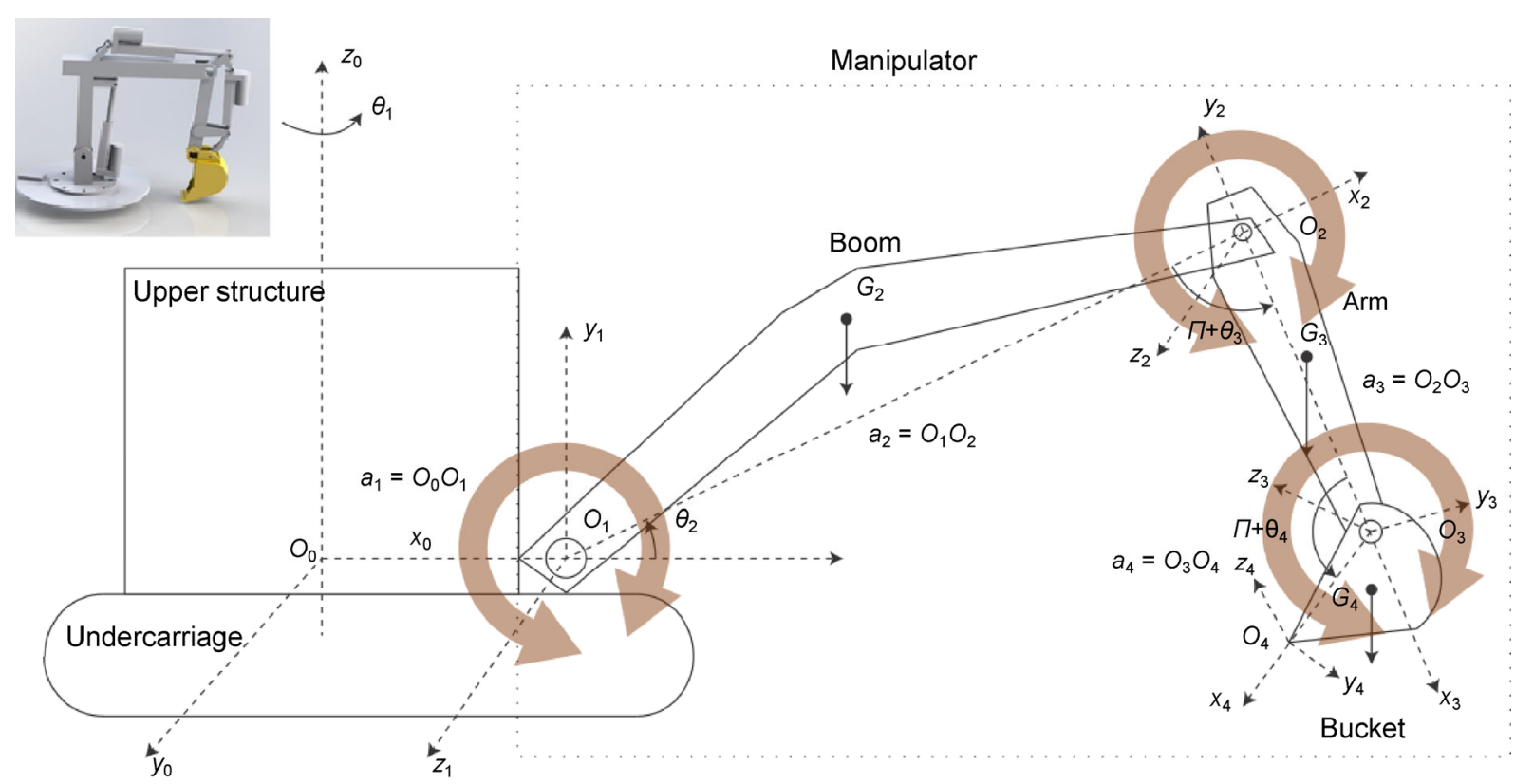

Fig. 4 The layout of a robot with a planar manipulator mechanism based on Ref. [55], the circle with arrows depicts the friction torques at rotary joints. The inset of the figure shows the rendering of a manipulator model generated within the computer aided design environment.

forces, $\Gamma$ is the input matrix corresponding to joint torques $\tau=\left[\tau_{1}, \tau_{2}, \tau_{3}, \tau_{4}\right]^{\mathrm{T}}$ and $\tau_{\mathrm{L}}$ represents equivalent soil-tool interaction torques. The first angle, $\boldsymbol{\theta}_{1}$ represents the rotation of the manipulator about the base of the excavator, which is usually assumed to be null magnitude since the manipulator operation is assumed to be immobile in that degree of freedom. This means that the manipulator remains planar during digging since it does not turn about the base during this task. Therefore, the model complexity and the computational effort are reduced.

The soil tool interaction force $F_{\mathrm{L}}$ is a highly nonlinear component, which acts on the end effector. Several researches are dedicated to the computation of soil-tool interaction forces [62-65]. The influence of the soil-tool interactions on the state variables of the manipulator would also affect the friction torque generated at the revolute joints. Therefore, simple friction models would be insufficient to capture the resulting frictional dynamics. In joint mechanism friction forces may be as high as $20 \%$ of the actuation force [7]. Simplification schemes may include (1) simplifying dynamics by ignoring some terms and correcting errors using feedback (e.g., non-linear friction effects, Coriolis's force and centripetal force which can be ignored at low link velocities but constitute a considerable component of forces at high speeds. The Coriolis's/Centripetal components cannot be corrected by feedback method.), or (2) tabulation lookup. Tabulation and interpolation method can be used to create a lookup table for pre-calculated values. Therefore, this technique cannot be employed when non-linear terms occur. Tabulation method cannot be applied to friction due to its high non-linearity. Recursive Newton formulation is more efficient than recursive Lagrangian formulation. However, they can be brought down to approximately the same computational time, making real time solution possible [66]. A diagrammatic representation of dynamics and control is given below in Fig. 5 .

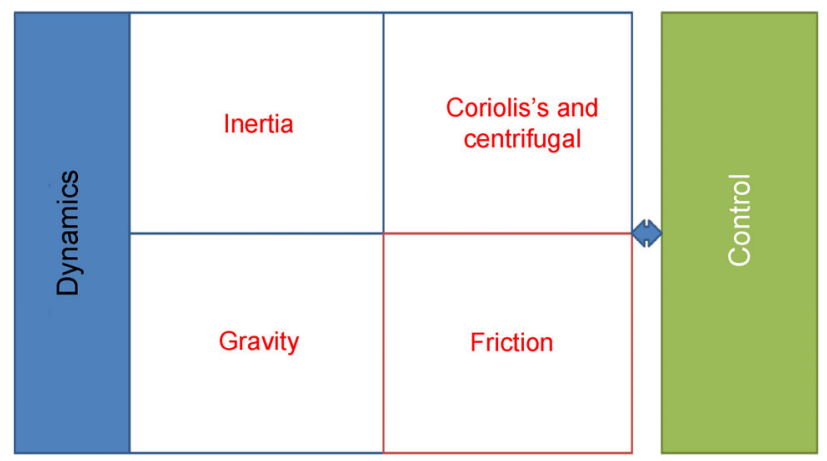

Fig. 5 Representation of the dynamics equation and its components. 
For dynamic systems with clearance, the combination of differential and algebraic equations (DAE) resulting in the equation of motion is given by [67]:

$$
\left[\begin{array}{cc}
\boldsymbol{M} & \boldsymbol{\phi}_{\mathrm{q}}^{\mathrm{T}} \\
\phi_{\mathrm{q}} & 0
\end{array}\right]\left[\begin{array}{l}
\ddot{q} \\
\lambda
\end{array}\right]=\left[\begin{array}{l}
g \\
\gamma
\end{array}\right]
$$

where $\boldsymbol{M}$ is the mass matrix, and $\phi_{\mathrm{q}}$ is the Jacobian matrix for the constraint equations. $\ddot{q}$ includes the generalised state accelerations. $\lambda$ denotes the Lagrange multipliers, $g$ is the generalised force vector, and $\gamma$ represents quadratic velocity terms dependent on velocity, position and time. This equation can be solved by using solution methods which are applicable to algebraic equations in the absence of redundant constraints. Baumgarte method is the most widely folloed stabilisation methods in solution of DAEs. In the case of redundant constrains, the augmented Lagrangian method is employed. Detailed formulation method is presented by Flores et al. in Ref. [67] and the model is employed in the majority of subsequent modelling works.

In the next section the progress in friction modelling has been presented.

\section{History of friction modelling}

While modelling the spatial behaviour, and the dynamics of mechanisms has made significant progress, it is necessary to capture the effects of friction in the joints. In classical modelling, the effect of friction is not considered. However, friction is defined as the tangential reaction force that occurs between two surfaces in contact, dependent on factors that include the contact geometry, the topology, relative velocity of surfaces in contact and displacement of surfaces, load and lubrication [23,68-71]. Friction is a complex phenomenon caused by the interaction of the surface and near surface regions of two interacting components as well as lubricants if present between such surfaces [72]. However, the classical friction model does little more than to give an approximation of friction forces in static analyses.

The selection of friction models is based on the operational condition during application. Several mentioned models include evaluation of physical friction and wear. Olson et al. [68] have examined several friction models which are available in the context of automatic control. Within the domain of control theory friction effects are addressed in dynamics by quantifying parameters as noise generated from the ensuing effects [73], however such an approach falls short to address the overall phenomena of friction and wear from the mechanical design approach.

In the forthcoming section, static and dynamic friction models are examined, with their brief history and modelling equations.

\subsection{Static friction models}

Literatures $[2,74]$ reveal preliminary inquiries into the nature of friction of interacting bodies. The postulates of friction according to Guillaume Amontons [75] are given as:

- The force of friction is directly proportional to the applied load, i.e., $\mu \propto W$.

- The force of friction is independent of the apparent area of contact.

- Kinetic friction, $\mu_{\mathrm{k}}$ is not proportional to (independent of) the sliding velocity.

Therefore, the simplest representation of friction can be given as

$$
F_{\mathrm{f}}=\mu W
$$

where the coefficient of friction $\mu$, is dependent on the mating materials in interaction, surface preparation and operating conditions. The force required to initiate movement is known as the static friction force. The force required to maintaining motion is called kinetic friction force. These different magnitudes with the value of frictional force at limiting conditions have a greater value compared to kinetic condition.

Coulomb proposed the simple roughness model in 1785 which is used for friction force calculation. It is a static model that has neither history nor states [7] and may be explained based on the quasi-static properties of materials. The Coulomb model has no dissipative component to it, which is a drawback [76]. It is given by Ref. [77].

$$
F_{\mathrm{c}}=\mu F_{\mathrm{n}} \operatorname{sign}(v)
$$

Also, shear failure is the predominant cause in sliding 
with friction. For static and Coulomb friction, the friction forces are proportional to the normal load. At low velocities, the shear strength of a solid lubricant film is high compared to the corresponding shear forces of the fluid film building up at higher velocities. The viscous friction can be represented by

$$
F_{\mathrm{v}}(v)=\sigma_{\mathrm{v}} v
$$

If the lubricating film is sufficient to separate the bodies in contact completely, the hydrodynamic effects become significant, i.e., the friction coefficient may increase with the velocity. Therefore, the friction force generated in lubricated systems normally decreases when the velocity increases from zero. This is called the Stribeck effect.

While the Coulomb and viscous friction models account for the fundamental modelling of friction at joints, the addition of Stribeck friction accounts for low velocity, high magnitude friction. The combined effects of the Coulomb, viscous and Stribeck components of friction is shown in Fig. 6. The mathematical representation of the combined effects of static friction models is given by:

$$
F_{\mathrm{f}}(v)=\mu F_{\mathrm{n}} \operatorname{sign}(v)+\sigma_{\mathrm{v}} v+F_{\mathrm{s}}(v)
$$

These effects, which have been evaluated initially for the linear sliding models, also apply to revolute models as revolute friction torque. Above mentioned model does not accurately capture friction and its effects. The requirement of dynamic friction models

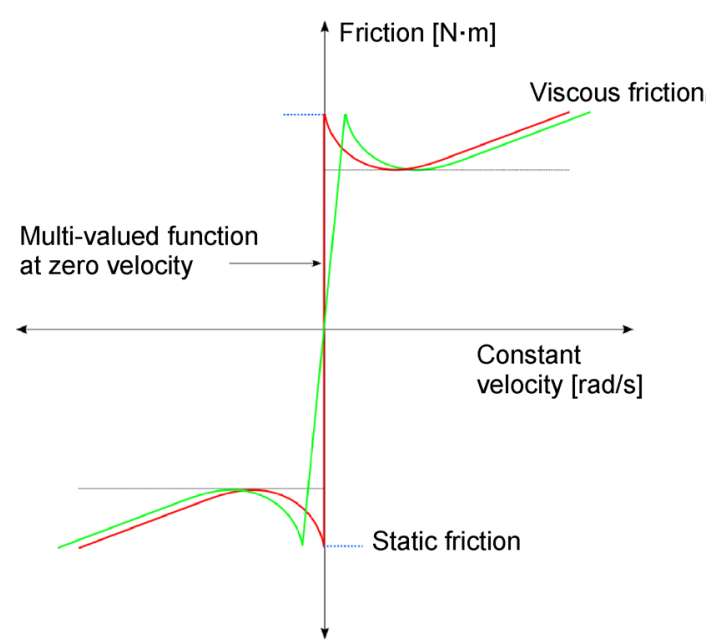

Fig. 6 The combined effect of Coulomb friction, viscous friction and low velocity Stribeck effect based on Ref. [78]. is highlighted which have been explained in the next section.

\subsection{Dynamic friction models}

The phenomenon of friction is being increasingly applied to modelling of dynamic systems and their control. Several models in literature include Dahl model (1968), Karnopp (1985), Bliman Sorin (1995), LuGre (1998) and the Leuven (2000) model. Classical friction models do not accurately predict limit cycle. For precision control applications, however the effect of friction cannot be ignored, i.e., micron level motion gradient in manipulator junctions may result in positioning various several orders higher at the end effector location. Physics motivated models such as generalised Maxwell slip model, Frenkel Kontrova, Tomlinson, Frenkel Kontrova Tomlinson model, Barridge Knopoff model, and Tomlinson models [77] are not presented here. These models improve accuracy of modelling however cannot be employed for control systems owing to their computational time requirement. Several friction models have been presented in literature incorporating dynamic friction models to enhance capturing the effects of friction. Friction model must account for the transition phenomena between static and kinetic contact, and account for hysteresis effect and direction reversals. These models have been introduced to bridge the gap in performance found in the static friction models, which have been explained in the previous section.

Developments in the dynamic friction models have occurred perhaps from the mid half of the twentieth century. The important models have been summarised in Eqs. (7)-(12). The key aspects included in these models are the genesis of friction, stick-slip phenomenon, hysteresis, friction lag and friction memory which make it more complicated and the same time capture friction effects better compared to static models which are presented in Section 4.1. Dahl model is among the first of such models [79]. According to Olsson et al. [68] both the LuGre model and the Bliman-Sorin developments on the Dahl model capture viscous friction, Stribeck friction and the phenomenon of stiction. The LuGre model adds the effect of damping to the Dahl model. Piatkowski [80] provides a recent analysis of Dahl and LuGre models. Dynamic 
friction models have been considered by Karnopp [81], Quinn, Kikuuwe [82, 83], Awrejcewicz and Kudra [84], and Wojewoda et al. [85].

Dahl Model-1968 [79, 80]:

$$
F=\sigma_{0} z
$$

where $z=v \operatorname{sgn}\left(1-\operatorname{sgn}(v) \frac{\sigma_{0} z}{F_{\mathrm{c}}}\right)\left|1-\operatorname{sgn}(v) \frac{\sigma_{0} z}{F_{\mathrm{c}}}\right|^{\delta_{\mathrm{p}}}$

Karnopp Friction model-1985, 2008 [81, 86]:

$$
F_{\text {friction }}= \begin{cases}-F_{\mathrm{c}} \cdot \operatorname{sgn}(\dot{x})-F_{\mathrm{v}} \dot{x} & |\dot{x}| \geqslant \mathrm{DV} \\
-\left(F_{\mathrm{ext}}-k x\right) & \left\{\begin{array}{l}
|\dot{x}|<D V \\
\left|F_{\text {ext }}-k x\right| \leqslant F_{\mathrm{s}}
\end{array}\right. \\
-F_{\mathrm{s}} \cdot \operatorname{sgn}\left(F_{\text {ext }}-k x\right) & \left\{\begin{array}{l}
|\dot{x}|<D V \\
\left|F_{\text {ext }}-k x\right|>F_{\mathrm{s}}
\end{array}\right.\end{cases}
$$

where $F_{\mathrm{c}}$ is the Coulomb friction coefficient, $F_{\mathrm{v}}$ is the viscous friction coefficient, $F_{\mathrm{s}}$ is the static friction coefficient, DV is the limit velocity and the $\operatorname{sgn}($.) function is given by

$$
\operatorname{sgn}(\alpha)= \begin{cases}1 & \alpha>1 \\ 0 & \alpha=1 \\ -1 & \alpha<1\end{cases}
$$

Bliman-Sorin Model-1995 [87, 88]:

$$
\frac{\mathrm{d} x}{\mathrm{~d} s}=A x_{\mathrm{s}}+B v_{\mathrm{s}}
$$

where

$$
F=C x_{\mathrm{s}}
$$

$$
A=\left(\begin{array}{cc}
\frac{-1}{\eta \varepsilon_{\mathrm{f}}} & 0 \\
0 & \frac{-1}{\varepsilon_{\mathrm{f}}}
\end{array}\right), \quad B=\left(\begin{array}{l}
f_{1} /\left(\eta \varepsilon_{\mathrm{f}}\right) \\
-f_{2} / \varepsilon_{\mathrm{f}}
\end{array}\right), C=\left(\begin{array}{ll}
1 & 1
\end{array}\right)
$$

LuGre Model-1998 [68, 89]:

$$
F=\sigma_{0} z+\sigma_{1} \dot{z}+\sigma_{2} \dot{z}
$$

where

$$
\begin{gathered}
\dot{z}=v-\frac{\sigma_{0}|v|}{s(v)} z \\
s(v)=F_{c}+\left(F_{s}-F_{c}\right) \exp \left(\left(-v / v_{s}\right)^{\delta_{v s}}\right)
\end{gathered}
$$

Leuven Model-2000 [72, 90]:

$$
\begin{gathered}
\frac{\mathrm{d} z}{\mathrm{~d} t}=v\left(1-\operatorname{sgn}\left(\frac{F_{\mathrm{d}}(z)}{s(v)-F_{\mathrm{b}}}\right)\left|\frac{F_{\mathrm{d}}(z)}{s(v)-F_{\mathrm{b}}}\right|^{n}\right) \\
F_{\mathrm{f}}=F_{\mathrm{h}}(z)+\sigma_{1} \frac{\mathrm{d} z}{\mathrm{~d} t}+\sigma_{2} v
\end{gathered}
$$

$F_{\mathrm{h}}(z)$ is the hysteresis force, $n$ is a coefficient used to transitions the shape curves, $s(v)$ is function which models the constant velocity behaviour, given by:

$$
s(v)=\operatorname{sgn}(v)\left(F_{\mathrm{c}}+\left(F_{\mathrm{a}}-F_{\mathrm{e}}\right) \mathrm{e}^{-\left(|v| / V_{\mathrm{a}}\right)^{\delta}}\right.
$$

Seven Parameter Friction model 1994 [45, 77]:

$$
\begin{gathered}
F_{\mathrm{f}}(x)=-k_{\mathrm{t}} x \text { (presliding) } \\
F_{\mathrm{f}}(v(t), t)=-\left(F_{\mathrm{c}}+F_{\mathrm{v}}|v(t)|\right)-\operatorname{sgn}\left(v(t) F_{\mathrm{s}}\left(v, t_{2}\right) \frac{1}{1+\left[v \frac{(t-\tau)}{v_{s}}\right]}\right.
\end{gathered}
$$

(Coulomb and viscous sliding)

$F_{s, a_{n}}=F_{s, a_{n-1}}+\left(F_{s, \infty}-F_{s, a_{n-1}}\right) \frac{t_{2}}{t_{2}+v}$ (Rising static frictionbreakaway)

Piedboeuf et al. [7] proposed an algorithm for computing joint friction in robotic simulations which includes Stribeck regime along with the stick-slip process validated against a planar robotic arm. At zero velocity, the friction value may be any value between $\pm F_{s}$ as shown in Fig. 6. To alleviate the problem introduced by bi-valued function at zero velocity, a gradient is introduced between the transition [91] and is reflected in Fig. 6. The solution to overcoming this non-unicity is to insert a linear slope across zero crossing where the function becomes bi-valued (applied similarly in [91, 92]).

Dahl Model is similar to the reset integrator model and includes (1) mechanism for zero velocity sticking and (2) application independent design. Disadvantages of the model are that (1) it does not generate a stiction force exceeding the sliding force unlike the other 4 models but can be modified to accommodate it and (2) lower accuracy compared to Karnopp and RI model.

Karnopp used bond-graph method to model the effects of friction for a two body system [81]. The model can be represented by Eq. (8). While this captures the energy aspect of the system, the disadvantage of the bond-graph equation is that it has to be formulated for 
every model. The order of Karnopp model [81, 86, 93] reduces at zero relative velocity between the surfaces. Advantages of this model include (1) stick-slip phenomenon included in the model and (2) 30\% faster execution. The drawbacks of the Karnopp model are that (1) the complexity of the model increases with increasing complexity of the dynamic system and (2) all combination possibilities of motion between the bodies must be considered. More detailed friction models such as the Dahl model and LuGre model (Eq. (10)) which account for the pre-sliding conditions have been presented in literature. Both Dahl and LuGre model are rate dependent because of which they cannot capture the reversal point memory. Swevers et al. [72] uses the LuGre model which performs satisfactorily for constant sliding velocity and suggests modification to it. In LuGre model the parameter $z$ can be interpreted as the average bristle deflection. A change in the magnitude of frictional force occurs due to the transition between static and kinetic phase breakaway phenomenon occurring. Therefore, the transitional friction needs to be considered. However, LuGre model does not account for hysteresis behaviour. Swevers et al. [72] model includes Stribeck friction in sliding, hysteretic behaviour in pre-sliding, frictional lag, varying breakaway and stick-slip behaviour, supported by experiments but does not account for material characteristics and the effect of loads on material variations. The Bliman Sorin model presented in Eq. (9) is modified form of LuGre model [77]. Leuven model Eq. (11) is a modification of LuGre model and includes hysteresis with nonlocal memory. The modified Leuven model presented in Ref. [90] addresses the issues of memory stack size and frictional force discontinuity at closure of frictional loop with Lueven model. De Wit et al. [94] described the loss of performance of high precision manipulators owing to the effects of friction. The effect of friction lag and the existence of a hysteretic relationship between friction and velocity are considered. Breakaway force can also vary according to dynamics of the contact. At microscopic contact dimensions the velocity between the contacts will be non-zero. Stick slip motion is also seen in joints. Friction compensation through observer method is used to develop the control system in such a case. The model captures friction phenomena while maintaining simplicity. The performance of the contact through start of motion to its end and the performance at various velocities have been incorporated into the system.

Haessig and Friedland [95] present two friction models of which one is based on the bristle formulation intended to capture "sticking" effect (Fig. 7) and the other is called "reset integrator" model which does not encompass sticking but is similar to Karnopp model. The process of initiation of friction is described as the interaction of peaks that initially resembles a spring damper with high stiffness that is reluctant to allow motion. Discontinuity of friction at zero velocity causes very short computational time steps and steep slopes where a linear bypass is implemented.

Reset integrator (RI) model uses an auxiliary integrator to represent the phenomena of stiction. Advantages of this model are: (1) it is application independent; (2) it does not require re-derivation to suit each application; (3) it accurately represents bonding effect of stick-slip friction force; (4) this is a logical model; (5) loads are calculated to accommodate sticking loads and damping term; (6) damping mode is different from bristle in that there are no two separate modes; (7) it is computationally efficient; (8) short time steps due to breaking bristles are avoided; and (9) selection of parameters is much simpler than that for bristle model. The procedure is listed in Haessig and Friedland [95]. Seven-parameter model Eq. (12) consists of a spring model to capture presliding and Coulomb, Viscous, Stribeck friction and friction lag.

The Bristle model presented in Fig. 7 is a simple algorithm which is (1) more efficient and accurate; (2) friction represented as many bristles which deflect with stiffness and damping, representative of surface

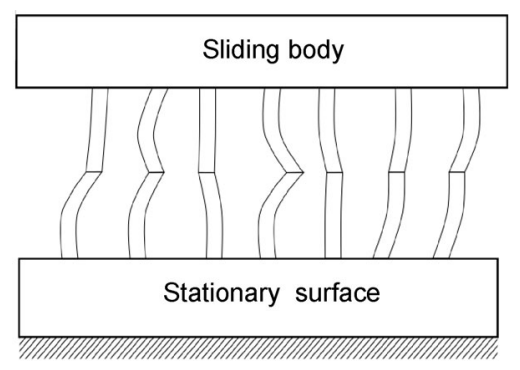

Fig. 7 The Bristle model shown above is one in which the contacting surfaces interact through bristles [95]. 
contact at joint; (3) frictional force is a function of velocity; (4) accurate model; (5) number of bristles control the fineness of the model. Disadvantages of the model are that (1) it is not efficient in terms of computational time; (2) fine spaced bristles cause successive short computational time steps and can decrease efficiency of the solution method or cause algorithm execution to fail; and (3) frictional force can become noisy signals.

Efficiency and accuracy of the models have been compared using fourth order Runge-Kutta method. The order of models in terms of computational efficiency are Dahl followed by Classical friction model, Karnopp, reset integral model and the bristle model. The selection of model is a trade-off between accuracy and computational efficiency, and the need for further comparison between RI and Dahl models is highlighted. The next section examines the issue of joint clearances in revolute joint contacts.

\section{Mechanistic models with clearance and friction}

A classification of mechanism models has been presented in Fig. 8. While the geometric and kinematic analyses provide partial insight into the system performance, dynamic models are required to fully describe complex interacting systems. Joints are introduced to provide some constraint on the motion of the mechanism. The joints can be dry or lubricated and contact can be intermittent or continuous and is usually determined by the area of application. Major simulation studies in the area have employed dry friction model. In an ideal mechanism, the joints would have a close fit leading to the classical mechanism model. In actual joints, however the problem of joint clearances exists. Clearances in mechanical systems may occur due to assemblage and manufacturing errors, usually result in undue wear, performance loss, reduction in stability, noise, and dynamic impact loads, and affect the transfer of system loads [96-98]. This alters the performance of the mechanism and affects the dynamics, control and durability of the mechanism. One example of this is the problem of manipulator end effector positioning [98]. Several factors such as the contact stiffness, surfaces condition, and lubricant need to be considered while

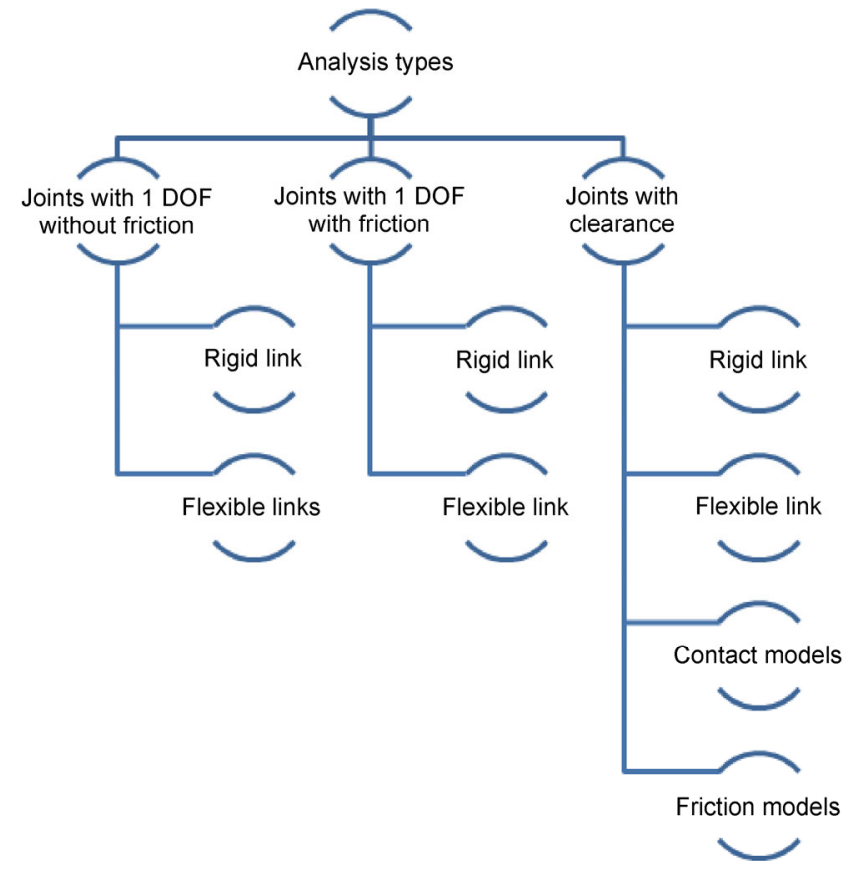

Fig. 8 Classification of manipulator dynamics research and problems.

developing the contact model for a joint with clearance. In literature the revolute joints are considered either in stand-alone configuration [98] or in assembled form of the slider crank mechanism [99] and four bar mechanism [20]. Wang also addressed a similar problem from the perspective of robotic manipulator environmental interaction. Multiple friction contacts in mechanical systems have been analysed in Ref. [100].

Modelling and simulation of multibody dynamics with joint clearances is relatively new area of research [96]. Three reviews are identified from literature namely Haines [101] —unlubricated revolute joints (1979), Flores (2010) [21] and Machado et al.-compliant contact force models (2012) [102]. The problem of multibody impact with friction was first analysed by Routh in 1891 [100]. The model of dynamic systems with mechanical clearance presented by Dubowsky and Freudenstein $[96,103]$ in a two part publication and introduced the concept of impact pair model in which the surfaces in contact are modelled as compliant, i.e., as spring damper contacts as shown in Fig. 9. In 1975, Hunt and Crossley [104] studied the influence of the coefficient of restitution between two impacting bodies based on the force-law approach and recorded the results from the numerical simulations. The issue of impacting multi-bodies with kinematic 


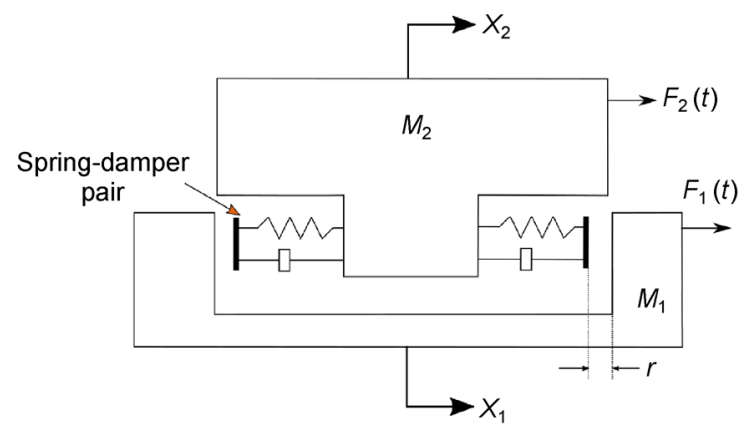

Fig. 9 Simple dynamic link coupling with clearance which leads to the "impact pair" condition based on Ref. [96].

contacts under the action of impulsive forces has been addressed by Lankarani and Nikravesh in [105]. Lankarani-Nikravesh contact model has been subsequently used in literature (Fig. 10). Rhee and Akay [106] investigated the revolute joint with clearance for a four bar mechanism and found a non-linear dependence on both the size of the clearance and coefficient of friction with a simple friction model for sliding friction. Friction and impact with joints clearance have been presented by Periera and Nikravesh [107] for intermittent motion with dry friction at the contact.

Spring-damper pair can be used to define connection between contacting surfaces, and are activated at the beginning of the contact. Contacting surfaces are initially assumed rigid. Energy dissipation cannot be modelled if the interaction is modelled exclusively by using only a spring connection because the spring has no dissipative component. To analyse the contactimpact the contact should be split into separate contact and departure events where each event is represented by switching function elements as shown in Fig. 11.

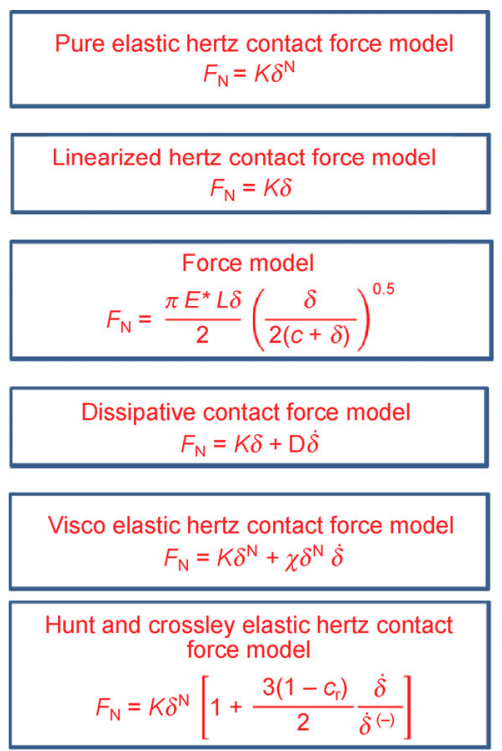

\begin{tabular}{|c|}
\hline Herbert and McWhannell model \\
$F_{\mathrm{N}}=K \delta^{\mathrm{N}}\left[1+\frac{6\left(1-c_{\mathrm{r}}\right)}{\left[\left(2 c_{\mathrm{r}}-1\right)^{2}+3\right]} \frac{\dot{\delta}}{\dot{\delta}^{(-)}}\right]$ \\
\hline Lee and Wang hysteresis model \\
$F_{\mathrm{N}}=K \delta^{\mathrm{N}}\left[1+\frac{3\left(1-c_{\mathrm{r}}\right)}{4} \frac{\dot{\delta}}{\dot{\delta}^{(-)}}\right]$ \\
\hline Lankarani-Nikravesh model \\
\hline$F_{\mathrm{N}}=K \delta^{\mathrm{N}}\left[1+\frac{3\left(1-c_{\mathrm{r}}^{2}\right)}{4} \frac{\dot{\delta}}{\dot{\delta}^{(-)}}\right]$ \\
\hline Gonthier model \\
$F_{\mathrm{N}}=K \delta^{\mathrm{N}}\left[1+\frac{\left(1-c_{\mathrm{r}}^{2}\right)}{c_{\mathrm{r}}} \frac{\dot{\delta}}{\dot{\delta}^{(-)}}\right]$ \\
\hline$F_{\mathrm{N}}=K \delta^{\mathrm{N}}\left[1+\frac{3\left(1-c_{\mathrm{r}}^{2}\right) \mathrm{e}^{2\left(1-c_{\mathrm{r}}\right)}}{4} \frac{\dot{\delta}}{\dot{\delta}^{(-)}}\right]$ \\
\hline \\
\hline$F_{\mathrm{N}}=K \delta^{\mathrm{N}}\left[1+\frac{8\left(1-c_{\mathrm{r}}\right)}{5 c_{\mathrm{r}}} \frac{\dot{\delta}}{\dot{\delta}^{(-)}}\right]$ \\
\hline
\end{tabular}

Fig. 10 Equations for the different contact models [102, 104, 108].
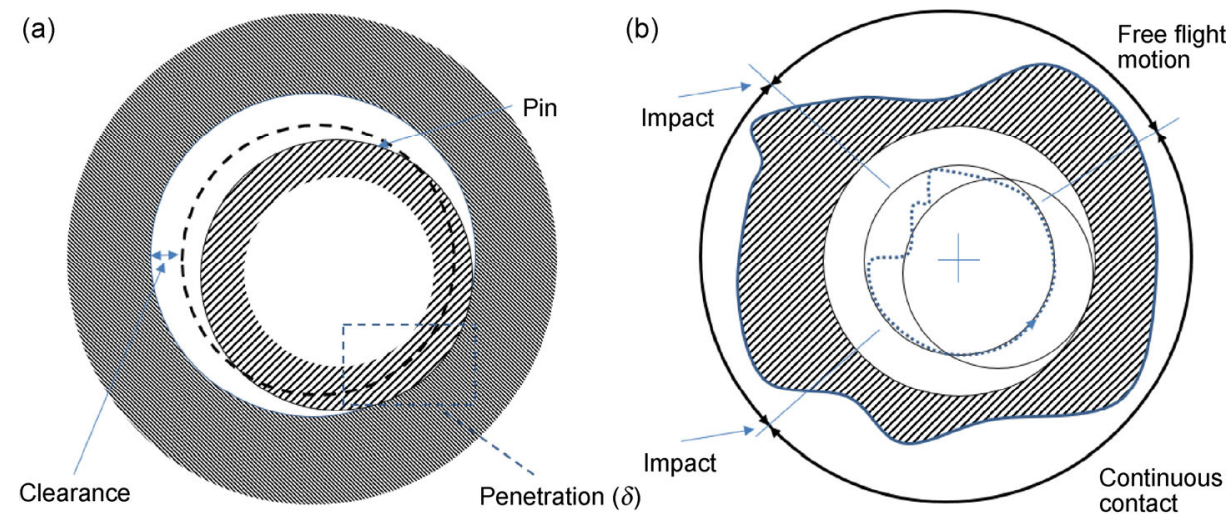

Fig. 11 The different modes in a revolute joint with clearance [109], and penetration in joints [110]. 
An alternative method of impact modelling for such contacts is the energy or Euler-Lagrangian method. Flores et al. [109] (see Fig. 12) has used momentum as a state variable of integration for two link pendulum and slider crank systems. Bauchau and Rodriguez [97] present a similar case in which finite element method (FEM) along with dynamic model has been proposed for a slider crank mechanism with flexible links.

Flores et al. [109] have analysed the dynamics of a slider-crank mechanism with clearance in the revolute joints. Hertzian contact model and Lankarani-Nikravesh contact impact model are used for calculating the contact parameters [111]. Koshy et al. [25] have evaluated the revolute joint with clearance for a rigid link slider crank mechanism focussing on the Hertzian contact model and extending the model to include damping and compared the results with experimental values. Hertz law for contacts is a static model as shown in Fig. 10, which has only a spring component that prevents energy dissipation. This violates the Law of Conservation of Energy at the contact. Hertz contact law is a nonlinear model. Energy transfer and conservation is a highly complex process. LankaraniNikravesh model is widely applicable compared to pure elastic force law models [25]. Acceleration parameters from the numerical simulations have been compared with values recorded from the slider crank mechanism. Clearance joints have an impact on the performance of mechanism as seen from experimental data [112]. It is worth noting that future analyses need to include joints material properties. Flores et al. [99] have concluded that lubrication alone alleviates much of the effects introduced by joint clearance

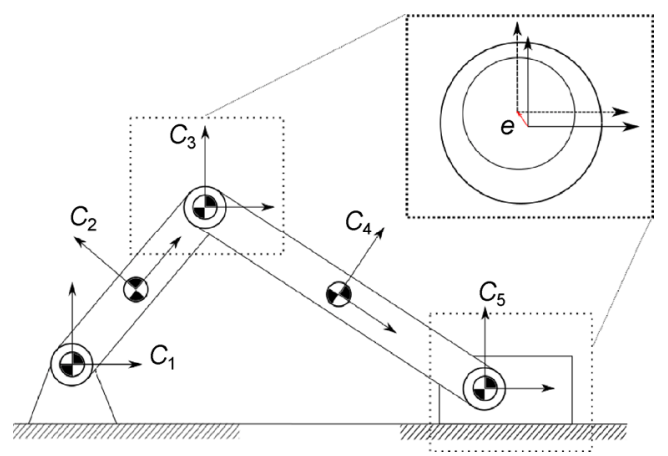

Fig. 12 Multibody system using slider crank mechanism with clearance. owing to the inherent damping qualities. This implies that the lubricant properties influence the dynamics of the system. Zhao et al. [113] presents revolute joint's dynamics with mixed lubrication model by using Lagrange method and incorporating finite element method (FEM) for modelling small end of a connecting rod in an internal combustion engine. Machado et al. [108] have compared the performance of various contact force models graphically. Mukras et al. [27] has presented a combined model including joint elasticity and viscosity for mechanism dynamics and is shown in Fig. 13.

Other models in literature include massless link in 4 bar linkage with clearance [114], three step contact model with three configurations: (1) free flight, (2) impact, and (3) sliding. [115] presents the three step model of the slider crank mechanism with reaction only on contact. [116] presents a four-link mechanism with three step model, using discontinuous method for pre-collision and post collision momentum balance, three mode approach in which the impact and sliding computed by using a contact force model. Non-ideal joints use force constraints and are modelled by Ravn [110]. According to contact impact pair, flexible mechanisms with multiple clearance [117], joint clearance for massless link and clearance joints have been proposed by Earles and $\mathrm{Wu}$ [118]. Slider crank mechanism with multiple clearance joints has been modelled by Yaqubi et al. [119]. Flores et al. [99] has studied the performance of lubricated journal bearings and slider crank

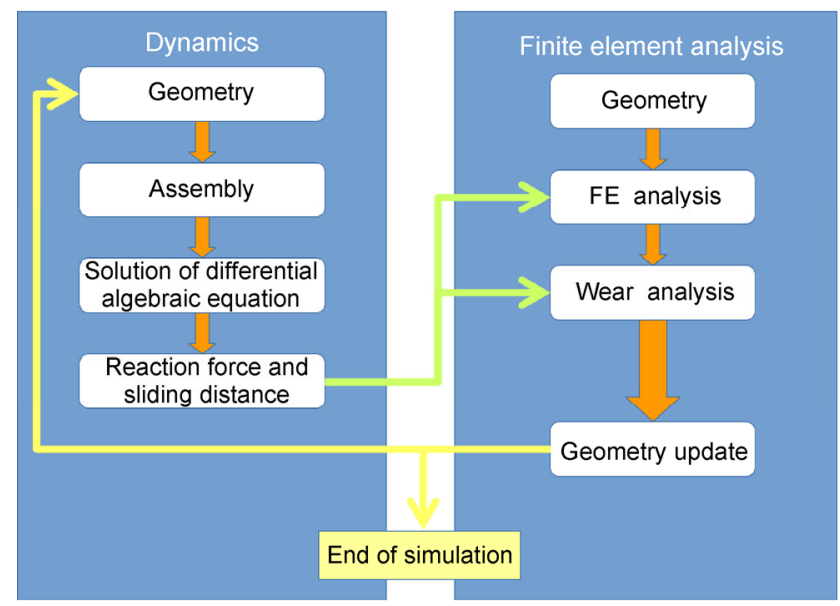

Fig. 13 Wear analysis integrated with the dynamics based on Ref. [27]. 
mechanism by using Pinkus-Sternlicht revolute model. Results from the publication shows that the model operates within the bounds of hydrodynamic lubrication theory. Elasto-hydrodynamic lubrication has been considered by Flores et al. [67] and Li et al. [120]. Several contact force models including pure elastic Hertzian contact force model, linearised Hertzian contact force model, force model, dissipative Spring Damper model, Gonthier model, Zhiying and Qishao model, Flores model, Visco-elastic Hertzian contact model, Hunt and Crossley model, Lee Wang hysteresis model, Lankarani-Nikravesh model and Hybrid model are presented in Fig. 10. A summary of these models and their successive improvements are presented in a survey of literature [98].

Three challenges that exist in multibody mechanical systems are (1) selection of appropriate constitutive law for the contact-impact event, (2) selection of appropriate contact stiffness and damping coefficient, and (3) quantification of energy transfer that occurs in such an event which leads to hysteresis [108]. Dynamics of collision may be classified as non-smooth dynamics formulation and the regularised approach (see Fig. 14).

A solution method for linear complementarity problem which can violate energy conservation principles has been used in Ref. [121]. Other solution methods include differential variation inequality (DVI) and Moreau's time stepping algorithm [21, 121]. However the limitation in Ref. [121] can be overcome

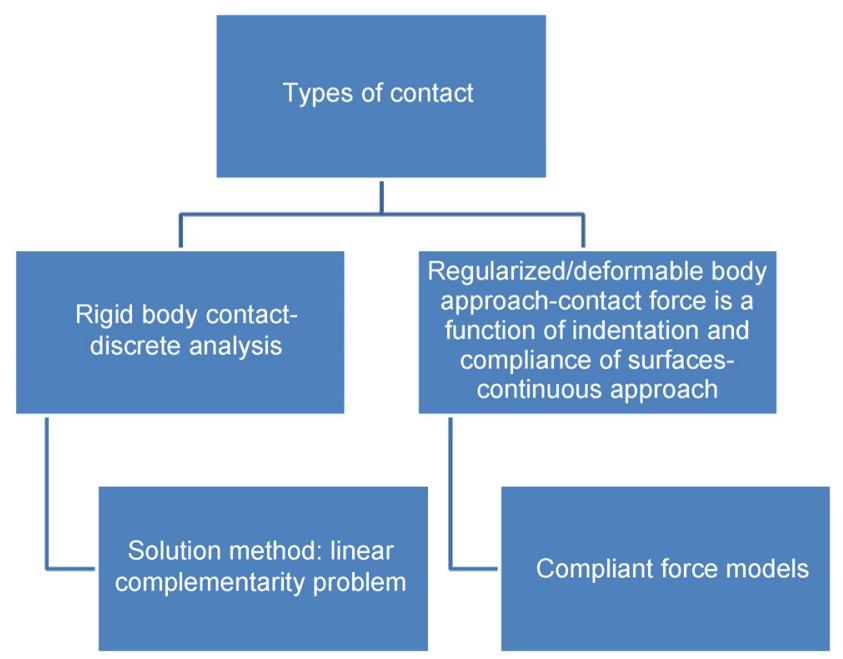

Fig. 14 Contact classification according to Machado et al. [102]. by choosing appropriate friction and degree of nonlinearity for complex contact conditions. In addition, the problem of energy dissipation without violating the energy conservation condition is critical since even for low energy impacts, energy is transformed into sound and mechanical vibrations, as a function of the coefficient of restitution whose definition is subjective. The coefficient of restitution, which is representative of energy dissipation, is dependent on factors such as geometry of the contacting surfaces, pre-impact velocity, local material properties, duration of contact, temperature and friction [102]. Machado et al. [102] and Flores et al. [99, 102] have highlighted the importance of choosing the appropriate model for the mechanism. The Gonthier model [26] and Flores models are suitable for moderate to low coefficients of restitution. These modified models show enhanced accuracy and the possibility of a unified model requires further investigation.

The best solution technique can be chosen such that the simulation results can be validated. There is sufficient evidence of consistent improvement in available models, which bring simulations closer to reality.

In joints with clearance, the condition of impact with motion exists and the sum of forces at the instance of impact can be represented by:

$$
F=F_{\mathrm{N}}+F_{\mathrm{T}}
$$

Although several impact models are presented in literature to compute the normal force at the point of impact in Fig. 10, most literature utilises modified Coulomb friction law for computing tangential force at the point of impact. The predominant model for friction employed in dynamic models with clearance in joints is Coulomb dry friction model or modified Coulomb dry friction model $[19,21,67,122]$. This can be explained by the fact that friction effect is only a minor component of the dynamic contact phenomenon in a joint with clearance and therefore is relegated in the analysis. Modified Coulomb friction law is given by [18]

$$
F_{\mathrm{T}}=-\mathcal{C}_{\mathrm{f}} \mathcal{C}_{\mathrm{d}} F_{\mathrm{N}} \frac{v_{\mathrm{T}}}{\left\|v_{\mathrm{T}}\right\|}
$$

where $F_{\mathrm{T}}$ is the tangential friction force, $c_{\mathrm{f}}$ is the friction 
coefficient, $c_{\mathrm{d}}$ is the dynamic friction coefficient, $F_{\mathrm{N}}$ is the normal force, and $v_{\mathrm{T}}$ is the relative tangential velocity. Dynamic correction coefficient $c_{\mathrm{d}}$ is given by

$$
c_{\mathrm{d}}= \begin{cases}0 & \text { if } v_{\mathrm{T}} \leqslant v_{0} \\ \frac{v_{\mathrm{T}}-v_{0}}{v_{1}-v_{0}} & \text { if } v_{0} \leqslant v_{T} \leqslant v_{1} \\ 1 & \text { if } v_{\mathrm{T}} \leqslant v_{1}\end{cases}
$$

where $v_{0}$ and $v_{1}$ are the transition velocities.

The use of dynamic correction factor $c_{\mathrm{d}}$ improves time stepping characteristics of the solution algorithm. The influence of $F_{\mathrm{N}}$ on $F_{\mathrm{T}}$ is therefore determined by impact model. The analysis of journal bearing with clearance joint is presented by Bai and Zhao [98] which incorporates a new contact force model. The essence of applying any such model is to capture the actual physical phenomenon of impact, rebound and movement as shown in Figs. 11 and 15. Although several models have been reported in literature, there is scope for improvement in the numerical prediction of joint performances and this requires a case by case evaluation depending on the number of factors affecting contact conditions and performance. Since the contacting surfaces are influenced by several factors, the interacting surfaces and their durability have been examined in the following section.

\section{Durability in harsh environments}

Durability is the capacity of the mechanism to perform the designated function and fulfil the intended design life without unexpected failure. Durability is critical in all cases especially in mechanisms that are designed for deployment in harsh environmental and operational conditions. Failure of equipment leads to halting progress, loss in revenues and could cause accidents, e.g., search and rescue missions in disaster stricken areas. Therefore design life cycle analysis is critical for specialised deployment in high risk environments [123].

The failure of mechanisms deployed in hazardous environments is discussed in literatures [36, 124, 125]. Design failure was recognised as a major factor. This also includes the failure of components. Mechanical durability of mechanisms subject to both constant and variable loading is highly desirable. Interacting surfaces of the manipulator revolute joint between various links are affected by multiple factors such as load, sliding speed, lubrication, heat and the influence of external agents such as corrosive fluids and debris. Therefore, failure in interacting surfaces may occur through a variety of modes such as plastic or viscoplastic deformation of material, wear of material through breakdown of lubrication, entry of debris into contact, crack propagation etc.

Durability of interacting surfaces can be enhanced through several methods. According to Ludema [126] there are three methods of modifying surfaces which are surface treatment [127], surface modification [128] and surface coating [129]. The effects of atmospheric agents on exposed metal alloy surfaces are studied and their durability has been evaluated in Refs. [130-132]. According to Bhushan [133], wear reduction can occur through non-uniformly tall, mean pressure of rounded peaks when the contacts should be lesser than the yield strength of the softer material in the contact. Surface hardening can also improve durability [134]. The use of suitable greases lubricants can also extend the life of the interacting surfaces $[135,136]$. The durability of grease can be further enhanced through additives [137]. Donnet and Erdemir [138] has presented a review of interfaces with attention to solid lubricants which extend wear life.
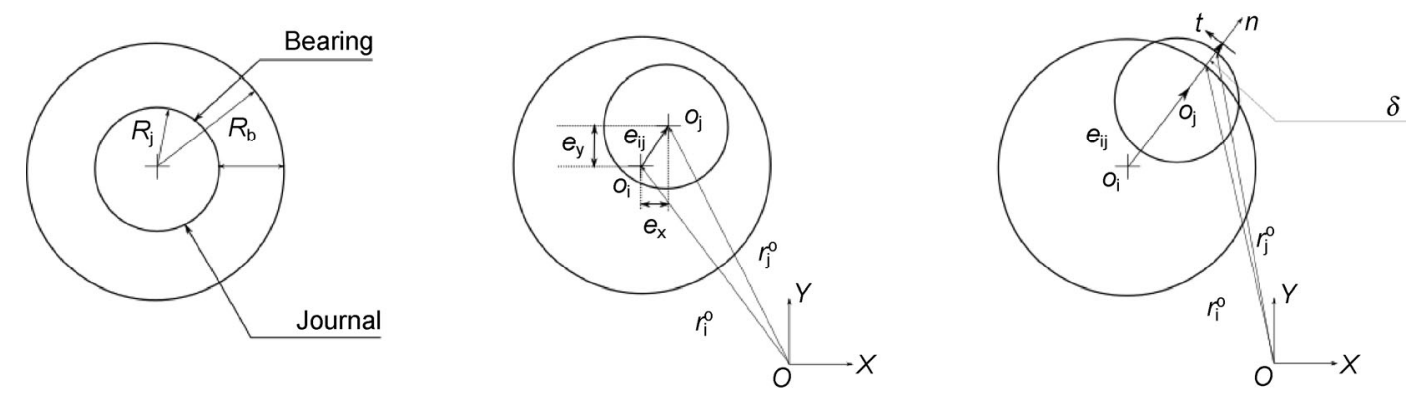

Fig. 15 Representation of the journal bearing with clearance for planar case based on Ref. [98] 
The enhancement of wear performance through diamond like carbon (DLC) coatings has also been discussed [138]. The use of diamond like carbon coatings has been presented in Ref. [139] and significantly reduces friction. Results of nano-composite coating, friction and wear analyses in rolling contact have been presented in Ref. [129]. Analysis of interaction at the joint for PEEK and Al 7075 alloys in robotic arms has been presented by Koike et al. [140]. Erdemir [141] has recommended the texturing of surfaces to improve the retention of lubrication and provide superior wear resistance in the contact. The addition of surfactants is also expected to enhance the contact durability by modifying the surface characteristics of the contact [142, 143].

Progress has been made from simple surface hardening to the use of surfactants to enhance wear resistance of contacting surfaces. Continued analysis of the influence of external agents in joint contacts and the influence on dynamics at the contact and investigation of the improvement of wear resistance and friction characteristics of the contact surfaces, surface modification and coatings is required for specialised applications. Furthermore, tribological testing is required to ensure the resilience of the interacting joints. Virtual prototyping and simulation [27, 144], along with the tribological experimentation is necessary for accurate prediction and to enhance the durability of interacting surfaces.

A rapid progress is desired in the modelling techniques and simulations, which bring it asymptotically close to actual physical models. In addition, the increasing reliance on simulation packages and virtual prototyping has been summarised in the forthcoming section.

\section{Software packages used in multi-body dynamics}

Several commercial software packages are available for the simulation of multibody dynamics [67]. For rigid link multibody mechanics simulation SimMechanics $1^{\text {st }}$ or $2^{\text {nd }}$ generation $[53,145]$ packages can be used. For joints with clearance packages like ADAMS [25,146, 147], COMPAMM, NEWEUL, DAP3D [148], MUBODYNA [102], RAPID and PARASOLIDS have been used [25] for interference detection. The problem can be formulated by using programming languages such as $\mathrm{C} / \mathrm{C}+$, Python or MATLAB m-code, depending on the intended application. However, the process of modelling the mechanics from first principles is often too tedious. Increasing reliance on software simulation packages has been observed with increasing model complexity, shorter project schedules, and higher productivity demand.

\section{Conclusions}

This paper covers literature in dynamic modelling and friction. It captures the evolution of mechanism and friction dynamics briefly. Key improvements in the area have been identified and presented. The effects of friction models in manipulator dynamics are seldom discussed because of the difficulty of incorporating all the influencing factors into a single model. However, with the improvements in computational and numerical modelling techniques, the frictional dynamics of mechanisms is more effectively analysed.

Rapid evolution of mechanical modelling methods over the latter half of the $20^{\text {th }}$ century includes advances in modelling techniques and computational methods [149]. These enable the modelling and the simulation of complex mechanisms with increased accuracy. The progress from simple kinematics to complex dynamics has been effected through the implementation of several advanced modelling techniques. Improvements in computational capacity have also enhanced the tools available resulting in the reduction of the overall process time.

Friction models have progressed from simple Coulomb, viscous and Stribeck friction models to the more comprehensive dynamic models such as the Leuven model. Some models incorporate wear in the contact by incorporating finite element computational techniques. High degree of non-linearity of the friction model and factors influencing the contact including the surface conditions, material properties, contact conditions and lubricating conditions are among several other factors and the interaction of these factors ensure that the convergence of a single friction modelling equation does not occur. To add to the 
complexity, dynamic modelling of mechanisms involves additional uncertainties such as the end effector trajectories [150] and environmental interaction [100]. Therefore, it will be necessary to examine each case individually to determine the important influencing factors in each case.

Progress in dynamic modelling methods with improved friction modelling is envisaged, e.g., a hybrid model that is capable of switching between different regimes. However, the unobservable transition conditions in contact makes this task tedious. Until such a unified model can be derived, smaller unified models addressing specific conditions of contact and frictional force generated in such contacts will be useful. This philosophy is consistent with literature. The influence of environments on contacts determines the life of the mechanism [129]. Improvement of the dynamic modelling techniques and tribo-analysis of the material at the contact is imperative within this context. Further analysis to determine the relationship among dynamics of mechanism, material properties, coefficient of friction and the influence of environments is needed (Fig. 16).

Tribo-testing carried out under differt loads, lubrication conditions and environmental influences would elucidate the dynamics and tribological performance of such contacts. The interaction between any two or more influencing factors may lead to accelerated failure at the joint or an inordinate rise in frictional resistance which are detrimental to the manipulator operation especially when precision positioning while handling heavy loads is required. The data generated thereof can be used to construct a specific but comprehensive model for the above-mentioned factors.

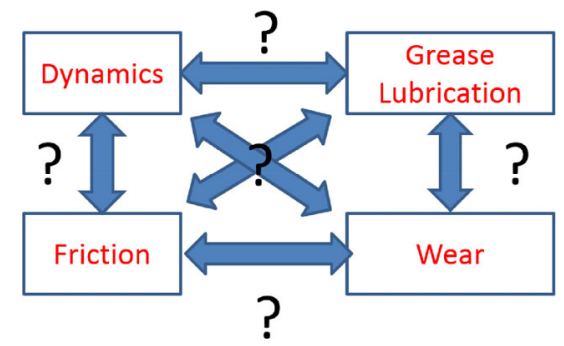

Fig. 16 The relationship between various components of a mechanism requires further study. After several decades of research there is no governing principle owing to the sheer complexity of the phenomenon involved.
Open Access: The articles published in this journal are distributed under the terms of the Creative Commons Attribution 4.0 International License (http:// creativecommons.org/licenses/by/4.0/), which permits unrestricted use, distribution, and reproduction in any medium, provided you give appropriate credit to the original author(s) and the source, provide a link to the Creative Commons license, and indicate if changes were made.

\section{References}

[1] Saha A, Wahi P, Bhattacharya B. Characterization of friction force and nature of bifurcation from experiments on a singledegree-of-freedom system with friction-induced vibrations. Tribol Int 98:. 220-228 (2016)

[2] Drucker D C. Coulomb friction, plasticity and limit loads. $J$ Appl Mech 21(1):71-74 (1953)

[3] Mukras S M. Analysis and design of planar multibody systems with revolute joint wear. Dissertations \& ThesesGradworks 268(5-6): 643-652 (2009)

[4] Tafazoli S, Lawrence P D, Salcudean S E. Identification of inertial and friction parameters for excavator arms. IEEE Trans Robot Autom 15(5): 966-971 (1999)

[5] Jonker J B, Waiboer R R, Aarts R G K M. Modelling of joint friction in robotic manipulators with gear transmissions. In Computational Methods in Applied Sciences. Springer, 2005: 221-243.

[6] Simoni L, Beschi M, Legnani G, Visioli A. Friction modeling with temperature effects for industrial robot manipulators. In 2015 IEEE/RSJ International Conference on Intelligent Robots and Systems (IROS), 2015: 3524-3529.

[7] Piedboeuf J-C, de Carufel J, Hurteau R. Friction and stickslip in robots: Simulation and experimentation. Multibody Sys Dyn 4(4): 341-354 (2000)

[8] Yao B, Tomizuka M. Adaptive control of robot manipulators in constrained motion. In American Control Conference. 1993: 1128-1132.

[9] Nguyen K D, Dankowicz H. Adaptive control of underactuated robots with unmodeled dynamics. Rob Auton Syst 64: 84-99 (2014)

[10] Al-Ashoor R A, Khorasani K, Patel R V, Al-Khalili A J. Adaptive control of flexible joint manipulators. In 1990 IEEE International Conference on Systems, Man, and Cybernetics Conference Proceedings, 1990: 627-632.

[11] Johnson K L. Contact mechanics. J Tribol 108(4): 464 (1986)

[12] Film thicknesses in lubricated Hertzian contacts (EHL). Part 1: Two-dimensional contacts (line contacts). Engineering Sciences Data Unit (ESDU) 85027, 2010. 
[13] Hess D P, Soom A. Friction at a lubricated line contact operating at oscillating sliding velocities. $J$ Tribol 112(1): 147 (1990)

[14] Tyfour W R, Beynon J H, Kapoor A. Deterioration of rolling contact fatigue life of pearlitic rail steel due to dry-wet rolling-sliding line contact. Wear 197(1): 255-265 (1996)

[15] Bilandi S T. Identification of frictional effects and structural dynamics for improved control of hydraulic manipulators. Journal of Crystal Growth 180(180): 157-166 (1961)

[16] Flores P, Ambrósio J, Claro J C P, Lankarani H M, Koshy C S. A study on dynamics of mechanical systems including joints with clearance and lubrication. Mech Mach Theory 41(3): 247-261 (2006)

[17] Dupac M, Noroozi S. Dynamic modeling and simulation of a rotating single link flexible robotic manipulator subject to quick stops. J Mech Eng 60(7-8): 475-482 (2014)

[18] Flores P, Ambrósio J, Claro J C P. Dynamic analysis for planar multibody mechanical systems with lubricated joints. Multibody Syst Dyn 12(1): 47-74 (2004)

[19] Askari E, Flores P, Dabirrahmani D, Appleyard R. Dynamic modeling and analysis of wear in spatial hard-on-hard couple hip replacements using multibody systems methodologies. Nonlinear Dyn 82(1-2): 1039-1058 (2015)

[20] Flores P. Modeling and simulation of wear in revolute clearance joints in multibody systems. Mech Mach Theory 44(6): 1211-1222 (2009)

[21] Flores P. A parametric study on the dynamic response of planar multibody systems with multiple clearance joints. Nonlinear Dyn 61(4): 633-653 (2010)

[22] Flores P. Compliant contact force approach for forward dynamic modeling and analysis of biomechanical systems. Procedia IUTAM 2: 58-67 (2011)

[23] Marques F, Flores P, Lankarani H M. On the frictional contacts in multibody system dynamics. In ECCOMAS Themat. Conf. Multibody Dyn., 2015: 565-576.

[24] Lankarani H M, Nikravesh P E. Canonical impulsemomentum equations for impact analysis of multibody systems. J Mech Des 114(1): 180-186 (1992)

[25] Koshy C S, Flores P, Lankarani H M. Study of the effect of contact force model on the dynamic response of mechanical systems with dry clearance joints: computational and experimental approaches. Nonlinear Dyn 73(1-2): 325-338 (2013)

[26] Marques F, Flores P, Lankarani H M. Study of friction force model parameters in multibody dynamics. In The 4th Joint International Conference on Multibody System Dynamics, 2016.

[27] Mukras S, Kim N H, Mauntler N A, Schmitz T L, Sawyer W G. Analysis of planar multibody systems with revolute joint wear. Wear 268(5-6): 643-652 (2010)

[28] Mukras S, Kim N H, Sawyer W G, Jackson D B, Bergquist L W. Numerical integration schemes and parallel computation for wear prediction using finite element method. Wear 266(7-8): 822-831 (2009)

[29] Lingard H, Cooke T, Gharaie E. A case study analysis of fatal incidents involving excavators in the Australian construction industry. Eng Constr Archit Manag 20(5): 488-504 (2013)

[30] Koivo A J. Kinematics of excavators (backhoes) for transferring surface material. J Aerosp Eng 7(1): 17-32 (1994)

[31] Vähä P K, Skibniewski M J. Dynamic model of excavator. $J$ Aerosp Eng 6(2): 148-158 (1993)

[32] Koivo A J, Thoma M, Kocaoglan E, Andrade-Cetto J. Modeling and control of excavator dynamics during digging operation. J Aerosp Eng 9(1): 10-18 (1996)

[33] Stentz A, Bares J, Singh S, Rowe P. Robotic excavator for autonomous truck loading. Auton Robots 7: 175-186 (1999)

[34] Seward D, Margrave F. LUCIE the robot excavator-design for system safety. In Robotics and Automation, 1996. Proceedings., 1996 IEEE International Conference, 1996: 963-968.

[35] Tafazoli S, Lawrence P D P, Chan D, Bachmann S, de Silva C. Parameter estimation and actuator friction analysis for a mini excavator. In Proceedings of the International Conference on Robotics and Automation, 1996: 329-334.

[36] Carlson J, Murphy R R. How UGVs physically fail in the field. IEEE Trans Robot 21(3): 423-437 (2005)

[37] Liu Y, Nejat G. Robotic urban search and rescue: a survey from the control perspective. J Intell Robot Syst 72(2): 147-165 (2013)

[38] Lioy P J, Weisel C P, Millette J R, Eisenreich S, Vallero D, Offenberg J, Buckley B, Turpin B, Zhong M, Cohen M D, Prophete C, Yang I, Stiles R, Chee G, Johnson W, Porcja R, Alimokhtari S, Hale R C, Weschler C, Chen L C. Characterization of the dust/smoke aerosol that settled east of the World Trade Center (WTC) in lower Manhattan after the collapse of the WTC 11 September 2001. Environ Health Perspect 110(7): 703-714 (2002)

[39] Blau P J. Introduction. In Friction Science and Technology. CRC Press, 2008: 1-16.

[40] Khan Z A, Saeed A, Gregory O, Ghafoor A. Biodiesel performance within internal combustion engine fuel system-A review. Tribol Ind 38(2): 197-213 (2016)

[41] Khan Z A, Hadfield M. Manufacturing induced residual stress influence on the rolling contact fatigue life performance of lubricated silicon nitride bearing materials. Mater Des 28(10): 2688-2693 (2007) 
[42] Khan Z A, Hadfield M, Tobe S, Wang Y. Ceramic rolling elements with ring crack defects-A residual stress approach. Mater Sci Eng A 404(1-2): 221-226 (2005)

[43] Khan Z A, Hadfield M, Tobe S, Wang Y. Residual stress variations during rolling contact fatigue of refrigerant lubricated silicon nitride bearing elements. Ceram Int 32(7): 751-754 (2006)

[44] Khan Z A, Hadfield M, Wang Y. Pressurised chamber design for conducting rolling contact experiments with liquid refrigerant lubrication. Mater Des 26(8): 680-689 (2005)

[45] Armstrong-Hélouvry B, Dupont P, De Wit C C. A survey of models, analysis tools and compensations methods for the control of machines with friction. Automatica 30(7): 10831138 (1994)

[46] Rahnejat H. Multi-body dynamics: Historical evolution and application. Proc Inst Mech Eng Part C J Mech Eng Sci 214(1): 149-173 (2000)

[47] Schiehlen W. Multibody system dynamics: Roots and perspectives. Multibody Syst Dyn 1(2): 149-188 (1997)

[48] Siciliano B, Khatib O. Springer Handbook of Robotics, 1st ed. Springer-Verlag Berlin Heidelberg, 2008.

[49] Uicker J J, Pennock G R, Shigley J E, McCarthy J M. Theory of machines and mechanisms. J Mech Design 125(3): 650 (2003)

[50] Groover Jr M P, Zimmers Jr E W. CAD/Cam: ComputerAided Design and Manufacturing, 1st ed. Upper Saddle River, NJ, USA: Prentice Hall PTR, 1997.

[51] Farhat N, Mata V, Diaz-Rodriguez M. Dynamic simulation of a parallel robot: Coulomb friction and stick slip in robot joints. Robotica 28: 35-45 (2014)

[52] Hachkowski M R, Peterson L D, Lake M S. Friction model of a revolute joint for a precision deployable spacecraft structure. J Spacecr Rockets 36(4): 591-598 (1999)

[53] Chacko V, Yu H. Multi-body simulation methods for rigid manipulators. Eurathlon/SHERPA, 2015.

[54] Donald B, Spong M W. Chapter 3: Forward Kinematics: The Denavit-Hartenberg Convention.

[55] Vähä P K, Skibniewski M J, Koivo A J. Excavator dynamics and effect of soil on digging. In Proc. 8th ISARC, Stuttgart, Ger., 1991: 297-306.

[56] Baiges-Valentin and Ivan J. Baiges-Valentin. Dynamic modeling of parallel manipulators. University of Florida, 1996.

[57] Visioli A, Legnani G. On the trajectory tracking control of industrial SCARA robot manipulators. IEEE Trans Ind Electron 49(1): 224-232 (2002)

[58] Patel B P, Prajapati J M. Dynamics of mini hydraulic backhoe excavator: A Lagrange-Euler (LE) approach. Int $J$ Mech Aerospace Ind Mechatron Manuf Eng 8(1): 202-211 (2014)
[59] Korayem M H, Shafei A M. Application of recursive Gibbs-Appell formulation in deriving the equations of motion of N-viscoelastic robotic manipulators in 3D space using Timoshenko Beam Theory. Acta Astronaut 83: 273-294 (2013)

[60] Piedboeuf J C. Kane's equations or Jourdain's principle? In Proc. 36th Midwest Symp Circuits Syst, 1993: 1471-1474.

[61] Šalinic S. Determination of joint reaction forces in a symbolic form in rigid multibody systems. Mech Mach Theory 46(11): 1796-1810 (2011)

[62] Obermayr M, Vrettos C, Eberhard P, Däuwel T. A discrete element model and its experimental validation for the prediction of draft forces in cohesive soil. $J$ Terramechanics 53: 93-104 (2014)

[63] Yousefi Moghaddam R, Kotchon A, Lipsett M G. Method and apparatus for on-line estimation of soil parameters during excavation. J Terramechanics 49(3-4): 173-181 (2012)

[64] Perumpral J V, Grisso R D, Desai C S, Perumpral J V, Grisso R D, Desai C S. A soil-tool model based on limit equilibrium analysis. Trans ASAE 26(4): 0991-0995 (1983)

[65] Shmulevich I. State of the art modeling of soil-tillage interaction using discrete element method. Soil Tillage Res 111(1): 41-53 (2010)

[66] Hollerbach J M. A recursive lagrangian formulation of manipulator dynamics. 1980.

[67] Flores P, Ambrósio J, Claro J C P, Lankarani H M. Multibody systems formulation. Lecture Notes in Applied \& Computational Mechanics 34: 47-66 (2008)

[68] Olsson H, Åström K J, Canudas de Wit C, Gäfvert M, Lischinsky P. Friction models and friction compensation. European Journal of Control 4(3): 176-195 (1998)

[69] Sohail T, Malik A M. Measuring Coulomb and viscous friction in revolute joint. NUST J Eng Sci 1(1): 112-116 (2008)

[70] Berger E. Friction modeling for dynamic system simulation. Appl Mech Rev 55(6): 535 (2002)

[71] Harrison J A, Gao G, Schall J D, Knippenberg M T, Mikulski P T. Friction between solids. Philos Trans A Math Phys Eng Sci 366: 1469-1495 (2008)

[72] Swevers J, Al-Bender F, Ganseman C G, Prajogo T. An integrated friction model structure with improved presliding behavior for accurate friction compensation. IEEE Trans Automat Contr 45(4): 675-686 (2000)

[73] Le Tien L, Albu-Schaeffer A, De Luca A, Hirzinger G. Friction observer and compensation for control of robots with joint torque measurement. In 2008 IEEE/RSJ Int. Conf. Intell. Robot. Syst. IROS, 2008: 3789-3795.

[74] Archard J F. Contact and rubbing of flat surfaces. J Appl Phys 24(8): 981-988 (1953) 
[75] Jin Z, Fisher J. Tribology in joint replacement. Joint Replace Technol 2008: 31-55 (2008)

[76] Tabor D. Friction-The present state of our understanding. J Lubr Technol 103(2): 169-179 (1981)

[77] van Geffen V. A study of friction models and friction compensation. 2009.

[78] Lischinsky P, Canudas de Wit C, Morel G. Friction compensation for an industrial hydraulic robot. IEEE Control Syst Mag 19(1): 25-32 (1999)

[79] Dahl P R. A solid friction model. Aerospace Corp El Segundo CA, No. TOR-0158 (3107-18)-1, 1968.

[80] Piatkowski T. Dahl and LuGre dynamic friction models-The analysis of selected properties. Mech Mach Theory 73: 91-100 (2014)

[81] Karnopp D. Computer simulation of stick-slip friction in mechanical dynamic systems. J Dyn Syst Meas Control 107(1): 100-103 (1985)

[82] Kikuuwe R, Takesue N, Sano A, Mochiyama H, Fujimoto H. Fixed-step friction simulation: From classical coulomb model to modern continuous models. In 2005 IEEE/RSJ Int. Conf. Intell. Robot. Syst. IROS, 2005: 3910-3917.

[83] Kikuuwe R, Takesue N, Sano A, Mochiyama H, Fujimoto H. Admittance and impedance representations of friction based on implicit Euler integration. IEEE Trans Robot 22(6): 1176-1188 (2006)

[84] Awrejcewicz J, Kudra G. Regular and chaotic dynamics of three coupled physical pendulums. In the International Conference of Applied Mechanics, Sacam, 2000.

[85] Wojewoda J, Stefański A, Wiercigroch M, Kapitaniak T. Hysteretic effects of dry friction: modelling and experimental studies. Philos Trans $R$ Soc London A Math Phys Eng Sci 366(1866): 747-765 (2008)

[86] Romano R A, Garcia C. Karnopp friction model identification for a real control valve. IFAC Proc 17(1): 14906-14911 (2008)

[87] Bliman P A, Sorine M. Easy-to-use realistic dry friction models for automatic control. In Proceedings of 3rd European Control Conference, 1995: 267-272.

[88] Gafvert M. Comparisons of two dynamic friction models. In IEEE International Conference on Control Applications, 1997: 386-391.

[89] Freidovich L, Robertsson A, Shiriaev A, Johansson R. LuGre-model-based friction compensation. IEEE Trans Control Syst Technol 18(1): 194-200 (2010)

[90] Lampaert V, Swevers J, Al-Bender F. Modification of the Leuven integrated friction model structure. IEEE Trans Automat Contr 47(4): 683-687 (2002)

[91] The Mathworks Inc. UK. Loaded-contact rotational friction. Mathworks Doc 2016: 2-4.
[92] The Mathworks Inc. UK. Translational friction. Mathworks Documentation, 2015.

[93] Bona B, Indri M. Friction compensation in robotics: An overview. In Proc. 44th IEEE Conf Decis Control Eur Control Conf CDC-ECC '05, 2005: 4360-4367.

[94] De Wit C C, Olsson H, Astrom K J, Lischinsky P. A new model for control of systems with friction. IEEE Trans Automat Contr 40(3): 419-425 (1995)

[95] Haessig D A, Friedland B. On the modeling and simulation of friction. In Am Control Conf, 1990: 1256-1261.

[96] Dubowsky S, Freudenstein F. Dynamic analysis of mechanical systems with clearances-Part 1: Formation of dynamic model. J Eng Ind 93(1) 305 (1971)

[97] Bauchau O A, Rodriguez J. Modeling of joints with clearance in flexible multibody systems. Int $J$ Solids Struct 39(1): 41-63 (2001)

[98] Bai Z F, Zhao Y. A hybrid contact force model of revolute joint with clearance for planar mechanical systems. Int $J$ Non Linear Mech 48: 15-36 (2013)

[99] Flores P, Ambrósio J, Claro J C P, Lankarani H M, Koshy C S. Lubricated revolute joints in rigid multibody systems. Nonlinear Dyn 56(3): 277-295 (2009)

[100] Wang Y. Simulation of mechanical systems with multiple frictional contacts. J Mech Des 116(2): 571 (1994)

[101] Haines R S. Survey: 2-dimensional motion and impact at revolute joints. Mech Mach Theory 15(5): 361-370 (1980)

[102] Machado M, Costa J, Seabra E, Flores P. The effect of the lubricated revolute joint parameters and hydrodynamic force models on the dynamic response of planar multibody systems. Nonlinear Dyn 69(1-2): 635-654 (2012)

[103] Dubowsky S, Freudenstein F. Dynamic analysis of mechanical systems with clearances- Part2: Dynamic response. J Eng Ind 93(1): 305-309 (1971)

[104] Hunt K H, Crossley F R E. Coefficient of restitution interpreted as damping in vibroimpact. J Appl Mech 42(2): 440 (1975)

[105] Lankarani H M, Nikravesh P E. A contact force model with hysteresis damping for impact analysis of multibody systems. J Mech Des 112(3): 369-376 (1990)

[106] Rhee J, Akay A. Dynamic response of revolute joint with clearance. Mech Mach Theory 31(1): 121-134 (1996)

[107] Pereira M S, Nikravesh P E. Impact dynamics of multibody systems with frictional contact using joint coordinates and canonical equations of motion. Nonlinear Dyn 9(1-2): 53-71 (1996)

[108] Machado M, Moreira P, Flores P, Lankarani H M. Compliant contact force models in multibody dynamics: Evolution of the Hertz contact theory. Mech Mach Theory 53: 99-121 (2012) 
[109] Flores P, Koshy C S, Lankarani H M, Ambrósio J, Claro J C P. Numerical and experimental investigation on multibody systems with revolute clearance joints. Nonlinear Dyn 65(4): 383-398 (2011)

[110] Ravn P. A continuous analysis method for planar multibody systems with joint clearance. Multibody Syst Dyn 2(1): 1-24 (1998)

[111] Dupac M. Dynamical analysis of a constrained flexible extensible link with rigid support and clearance. $J$ Theoret Appl Mech 52(3): 665-676 (2014)

[112] Azimi Olyaei A, Ghazavi M R. Stabilizing slider-crank mechanism with clearance joints. Mech Mach Theory 53: 17-29 (2012)

[113] Zhao B, Zhang Z-N, Fang C, Dai X-D, Xie Y-B. Modeling and analysis of planar multibody system with mixed lubricated revolute joint. Tribol Int 98: 229-241 (2016)

[114] Furuhashi T, Morita N, Matsuura M. Research on dynamics of four-bar linkage with clearances at turning pairs: 1st report, general theory using continuous contact model. Bull JSME 21(153): 518-523 (1978)

[115] Farahanchi F, Shaw S W. Chaotic and periodic dynamics of a slider-crank mechanism with slider clearance. $J$ Sound Vib 177(3): 307-324 (1994)

[116] Khulief Y A, Shabana A A. A continuous force model for the impact analysis of flexible multibody systems. Mech Mach Theory 22(3): 213-224 (1987)

[117] Dubowsky S, Gardner T N. Dynamic interactions of link elasticity and clearance connections in planar mechanical systems. J Eng Ind 97(2): 652-661 (1975)

[118] Earles S W E, Wu C L S. Motion analysis of a rigid link mechanism with clearance at a bearing using Lagrangian mechanics and digital computation. J Mech 83-89 (1973)

[119] Yaqubi S, Dardel M, Daniali H M, Hassan M, Ghasemi M H. Modeling and control of crank-slider mechanism with multiple clearance joints. Multibody Syst Dyn 36(2): 143-167 (2016)

[120] Li P, Chen W, Li D, Yu R. A novel transition model for lubricated revolute joints in planar multibody systems. Multibody Syst Dyn 36(3): 279-294 (2016)

[121] Flores P, Leine R, Glocker C. Modeling and analysis of planar rigid multibody systems with translational clearance joints based on the non-smooth dynamics approach. Multibody Syst Dyn 23(2): 165-190 (2010)

[122] Flores P, Ambrósio J. Revolute joints with clearance in multibody systems. Comput Struct 82(17-19): 1359-1369 (2004)

[123] Chytka T M, Brown R W, Shih A T, Reeves J D, Dempsey J A. An integrated approach to life cycle analysis. In 11th
AIAA/ISSMO Multidiscip Anal Optim Conf, 2006: 13601374.

[124] Carlson J, Murphy R R. Reliability analysis of mobile robots. In 2003 IEEE Int Conf Robot Autom, 2003: 274-281.

[125] Wang Z. Design study of an earthquake rescue robot. Durham University, 2004.

[126] Ludema K C. Friction, Wear, Lubrication - A Textbook in Tribology. CRC Press, 1996.

[127] Chang S-H, Huang K-T, Wang Y-H. Effects of thermal erosion and wear resistance on AISI H13 tool steel by various surface treatments. Mater Trans 53(4): 745-751 (2012)

[128] Wakuda M, Yamauchi Y, Kanzaki S, Yasuda Y. Effect of surface texturing on friction reduction between ceramic and steel materials under lubricated sliding contact. Wear 254(3-4): 356-363 (2003)

[129] Bajwa R S, Khan Z A, Bakolas V, Braun W. Waterlubricated Ni-based composite $\left(\mathrm{Ni}-\mathrm{Al}_{2} \mathrm{O}_{3}, \mathrm{Ni}-\mathrm{SiC}\right.$ and $\left.\mathrm{Ni}-\mathrm{ZrO}_{2}\right)$ thin film coatings for industrial applications. Acta Metall Sin 29(1): 8-16 (2016)

[130] Saeed A. Sustainable methodology of conserving historic military vehicles. Bournemouth University, 2013.

[131] Nazir M H, Khan Z A, Stokes K R. A holistic mathematical modelling and simulation for cathodic delamination mechanism-A novel and an efficient approach. $J$ Adhes Sci Technol 29(22): 2475-2513 (2015)

[132] Nazir M H, Khan Z A, Stokes K R. Optimisation of interface roughness and coating thickness to maximise coatingsubstrate adhesion - a failure prediction and reliability assessment modelling. J Adhes Sci Technol 29(14): 14151445 (2015)

[133] Bhushan B. Contact mechanics of rough surfaces in tribology: multiple asperity contact. Tribol Lett 4(1): 1-35 (1998)

[134] Totik Y, Sadeler R, Altun H, Gavgali M. The effects of induction hardening on wear properties of AISI 4140 steel in dry sliding conditions. Mater Des 24(1): 25-30 (2003)

[135] Types and applications of lubricating greases. In Tribology Series, 1992: 664-696.

[136] De Laurentis N, Kadiric A, Lugt P, Cann P M E. The influence of bearing grease composition on friction in rolling/sliding concentrated contacts. Tribol Int 94: 624632 (2016)

[137] Cann P M E. Understanding grease lubrication. Tribol Ser 31: 573-581 (1996)

[138] Donnet C, Erdemir A. Historical developments and new trends in tribological and solid lubricant coatings. Surf Coat Technol 180-181: 76-84 (2004)

[139] Erdemir A, Eryilmaz O L, Fenske G. Synthesis of diamondlike carbon films with superlow friction and wear properties. J Vac Sci Technol A 18(4): 1987-1992 (2000) 
[140] Koike H, Kanemasu K, Itakura K,. Wear and transmission error between PEEK bush and 7075 aluminium alloy cam plate components in robot joints. Appl Mech Mater 307: 3-8 (2013)

[141] Erdemir A. Review of engineered tribological interfaces for improved boundary lubrication. Tribol Int 38(3): 249-256 (2005)

[142] Sahoo P, Das S K. Tribology of electroless nickel coatingsA review. Mater Des 32(4): 1760-1775 (2011)

[143] Zhang J, Meng Y, Tian Y, Zhang X. Effect of concentration and addition of ions on the adsorption of sodium dodecyl sulfate on stainless steel surface in aqueous solutions. Colloids Surfaces A Physicochem Eng Asp 484: 408-415 (2015)

[144] Choi S H, Cheung H H. A versatile virtual prototyping system for rapid product development. Comput Ind 59(5): 477-488 (2008)

[145] Schlotter M. Multibody system simulation with simmechanics. University of Canterbury, 2003.

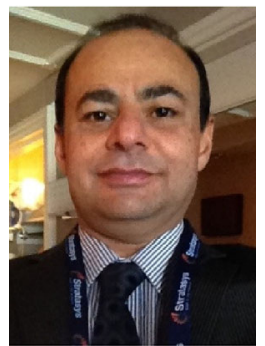

Zulfiqar A. KHAN. He is a professor of design, engineering \& computing at Bournemouth University, UK. He completed his BEng (Hons) and MEng (Hons) degrees in mechanical engineering and a PhD degree in tribology. He has previously worked in automotive, aircraft industries and GTZ United Nations energy savings technologies for several years. His research expertise includes corrosion fatigue, rolling contact fatigue, tribology and nanocoating with over 120 publications and a handbook on pressure vessel steel. He is currently leading a research portfolio of six industrial projects
[146] Tuominen M. Multibody simulations as a product development tool: Introduction to ADAMS and two analyses. Aalto University School of Engineering, 2015.

[147] Ben Abdallah M A, Khemili I, Aifaoui N. Numerical investigation of a flexible slider-crank mechanism with multijoints with clearance. Multibody System Dynamics 38(2): 173-199 (2016)

[148] Ambrósio J, Verissimo P. Improved bushing models for general multibody systems and vehicle dynamics. Multibody Syst Dyn 22(4): 341-365 (2009)

[149] Khurshid A, Zulfiqar K, Chacko V, Ghafoor A, Malik M A, Ayaz Y. Modelling and simulation of a manipulator with stable viscoelastic grasping incorporating friction. Tribol Ind 38(4): 559-574 (2016)

[150] Chacko V, Yu H, Cang S, Vladareanu L. State of the art in excavators. In International Conference on Advanced Mechatronic Systems, ICAMechS, 2014: 481-488.

within NanoCorr, Energy \& Modelling (NCEM) at Bournemouth University.

This review is part of a wider multidisciplinary research within NCEM led by Professor Khan and focuses on dynamic modelling and simulation to optimise friction through surface engineering within interacting joints applied in harsh environments. Authors are delighted to have put this work together to be available to scientists, academics, researchers, professionals and students to engage in the design for durability and reliability through a multidisciplinary approach to bring about societal, economic and environmental benefits. 